\title{
Software solution to design energy-efficient retrofitting projects at district scale
}

Susana Martín-Toral MEng

Researcher in ICT for Energy Efficiency and Sustainability, Energy Division, Cartif Technology Centre, Boecillo, Spain (Orcid:0000-0002-1867-878X) (corresponding author: susmar@cartif.es)

\section{Víctor I. Serna-González MEng}

Researcher in ICT for Energy Efficiency and Sustainability, Energy Division, Cartif Technology Centre, Boecillo, Spain (Orcid:0000-0003-4345-7476)

\section{Sonia Álvarez-Díaz MSc}

Researcher in Information Modeling, Simulation and Design, Energy Division, Cartif Technology Centre, Boecillo, Spain (Orcid:0000-0001-7868-4201)

\section{Miguel Á. García-Fuentes PhD}

Researcher in Information Modeling, Simulation and Design, Energy Division, Cartif Technology Centre, Boecillo, Spain (Orcid:0000-0001-6739-599X)
Gema Hernández-Moral MSc

Researcher in Information Modeling, Simulation and Design, Energy Division,

Cartif Technology Centre, Boecillo, Spain (Orcid:0000-0002-5094-0338)

Álvaro Sicilia-Gómez PhD

Researcher in ICT for Smart Cities and Sustainability, ARC, La Salle Engineering and Architecture, Ramon Llull University, Barcelona, Spain (Orcid:0000-0001-6335-7558)

\section{Gonçal Costa-Jutglar PhD}

Researcher in ICT for Smart Cities and Sustainability, ARC, La Salle Engineering and Architecture, Ramon Llull University, Barcelona, Spain (Orcid:0000-0001-9168-680X)

The EU strategies to reduce carbon dioxide emissions highlight the importance of renovating the existing building stock. It is one of the most contributing sectors to these undesired emissions to the atmosphere. The business-as-usual practices for designing energy-efficient retrofitting projects are still too time consuming and imprecise, and their supporting tools are not interconnected, provoking a lack of trust within the sector, particularly from investors. There is a need to improve these practices by reducing the errors and the time required to evaluate retrofitting alternatives to select the most appropriate according to the stakeholders' priorities. To address this gap, the Optimised Energy Efficient Design Platform for Refurbishment at District Level (OptEEmAL) solution enables the automatic generation of scenarios of energy conservation measures and their simulation and optimisation, based on data provided by the users. This solution automatically launches and connects the processes that the different stakeholders usually carry out in a long period of time. This allows testing a more varied set of solutions and engages stakeholders along the process supported by the integrated project delivery approach. As a result, time is reduced, as well as errors and, therefore, costs, which will lead to increase in efficiency and confidence among stakeholders.

\section{Introduction}

The issue of renovating existing buildings is an essential pillar in the energy transition. This is acknowledged within the several regulations and directives that have set up a framework to foster the energy-efficient retrofitting of buildings and to unlock the untapped potential existing in this sector. Thus, in 2012, the energy efficiency directive (EC, 2012) introduced the requirement to reach a $3 \%$ renovation target and established the need to deliver long-term renovation strategies (LTRSs) for EU Member States. The revised energy performance of buildings directive in 2018 (EC, 2018) increased the challenge for LTRSs to work towards the overall target of reducing the carbon dioxide emissions of the building stock by 2050 , setting the scene for a big transformation of the construction sector to deal with this target. Thus, new methods, tools and supporting elements are required to respond adequately to this challenge.

Different studies and methodologies have been proposed in order to evaluate building performance and to design strategies to support energy-efficient building retrofitting (Ozarisoy and Elsharkawy, 2019), often focused on specific areas or specific case studies. There exist some tools that can support decision making, as those listed by Sauer and Pedrola (2014). However, the design of energy-efficient retrofitting projects poses an elevated number of challenges when evaluating candidate retrofitting alternatives (Ozarisoy and Altan, 2019) that are not usually tackled by these tools. Apart from the fragmentation of the retrofitting sector, with several stakeholders with different and sometimes conflicting interests, from a technical perspective, the selection of indicators, generation of candidate retrofitting scenarios or the related simulation models are sometimes too time consuming and prone to human errors (Berkeley et al., 2015). These problems that are evident at the building level, where savings ranging from 20 to $60 \%$ are achieved (Ma et al., 2012), exponentially grow when tackling greater scales, such as the district level, where new interactions and flows appear, as well as new potential technologies to implement. In this sense, once technical maturity is achieved, the critical size makes a difference in attaining bankable interventions (Gee and Dijol, 2013).

Acknowledging all these issues, the research activities carried out in the Optimised Energy Efficient Design Platform for Refurbishment at District Level (OptEEmAL) project had as an output the design and development of a platform that implements various processes to support the design of energy-efficient retrofitting projects at the district scale (García-Fuentes et al., 2016). The main functionalities offered by the platform are the integration of data (coming from both the users and other sources) and generation of baseline data models, the simulation of baseline conditions and the generation of candidate retrofitting scenarios as 
Smart Infrastructure and Construction

Volume 172 Issue 3
Software solution to design energy-

efficient retrofitting projects at district

scale

Martín-Toral, Serna-González, Álvarez-Díaz et al. a combination of energy conservation measures (ECMs) modelled and integrated within a digital catalogue - and their evaluation and optimisation against a set of district performance indicators (DPIs) that are weighted considering the users' preferences and conditions.

All these functionalities are delivered by a set of modules that have been deployed and connected through appropriate interfaces to ensure communication among them. With a (micro)serviceoriented architecture and a publish-subscribe pattern, the OptEEmAL platform is able to interact with three different sets of stakeholders: owner, prime designer and prime constructor, chosen as main actors from the list provided by the integrated project delivery (IPD) paradigm (AIACC, 2014). They do so through a set of user-friendly graphical interfaces that allow them to perform the steps that belong to the process of designing energy-efficient retrofitting projects. Thus, by delivering automatic processes that are manually performed in the business-as-usual, this platform helps reduce errors, time and, therefore, costs to the stakeholders (Martín et al., 2019).

This paper presents the OptEEmAL platform and describes its high-level architecture, data representations and transformations, functional modules, interoperability and integration among them and the testing activities that have been performed to ensure its functioning. Results of the validation of the tool in a real district located in Valladolid, Spain, are also shown to demonstrate the feasibility and reliability of the solution.

\section{High-level architecture}

Taking into account the main objective of the OptEEmAL solution, this section details a high-level overview of the specific functionality expected for all the key components associated with the OptEEmAL architecture. This architecture is composed of a three-layer structure namely, the data layer, the business logic layer and the application layer, which altogether offer a holistic service-oriented platform able to integrate interoperable modules/tools to generate optimised district retrofitting scenarios. This approach is implemented by analysing the needs of each stakeholder in an IPD group and deriving from this analysis the interactions among them that are required, as well as the amount of information that each stakeholder needs. In this sense, the approach integrates some organisational and informational aspects that support a working method defined in IPD. However, even though a further analysis of these sociotechnical systems would be advisable, the main focus of OptEEmAL is broader and not restricted to these users' interactions.

In order to collect all these needs properly, a deeper analysis of the platform requirements is fundamental as the starting point to the design of the OptEEmAL architecture.

On the other hand, the interoperability of any information and communication technology solution can be granted through the use of existing technologies and standards (well-known and wellestablished communication protocols, data models and interface standard definitions). In the context of the OptEEmAL solution, the interoperability requirement is crucial since OptEEmAL needs to be interconnected to different internal and external services, data sources and tools. A common data representation, in the form of a district data model (DDM), is also needed to obtain a common way of interacting among all the different elements. All these needs are presented in the following subsections.

\subsection{Analysis of functional requirements}

The OptEEmAL solution aims to develop an optimised energyefficient design platform for refurbishment at the district level, which delivers an optimised, integrated and systemic design based on an IPD approach for building and district retrofitting projects, reducing time delivery and uncertainties, resulting in improved solutions when compared with business-as-usual practices.

To be able to reach the previous objective, the OptEEmAL platform requires integrating the five main pillars presented in Figure 1:

- 1 - A building information modelling (BIM)-based information exchange approach to enhance collaboration between stakeholders and improve information flows within the design process; three-dimensional (3D) and geographic representations of the district in the form of CityGML files are also considered here to enrich the district model generation.

- 2 - An IPD-based retrofitting design approach, to facilitate communication, knowledge sharing and consensus among interested stakeholders as the owner, primer designer or prime constructor.

- 3-A catalogue of ECMs considering the scale of implementation and providing all the needed data for the evaluation of the design alternatives.

- 4 - A multi-criteria decision analysis (MCDA) approach for decision making integrating the interests of the stakeholders and making use of well-established indicators at the building and district levels.

- 5 - A semantic data model and data-mapping process to ensure interoperability among the platform components and consistency of communications.

These five essential pillars have been covered in the OptEEmAL solution in different research lines, identifying in each of them the main requirements for the indicated functionalities (OptEEmAL Consortium, 2016a), specified in the following.

From the end-user point of view (pillar 2), a set of requirements has been collected related to the input data process to evaluate users' objectives and initial conditions (OptEEmAL Consortium, 2016b, 2016c). In that sense, data needed to build the baseline model of the district and to compare district retrofitting scenarios are required by the platform. To address the multiple objectives of the project, these data come in four different forms: BIM models representing the buildings under evaluation with the standard Industry Foundation Classes (IFC) (ISO, 2013) for the building scale, a CityGML (OGC, 2012) model representing the district scale, contextual data (climate, 

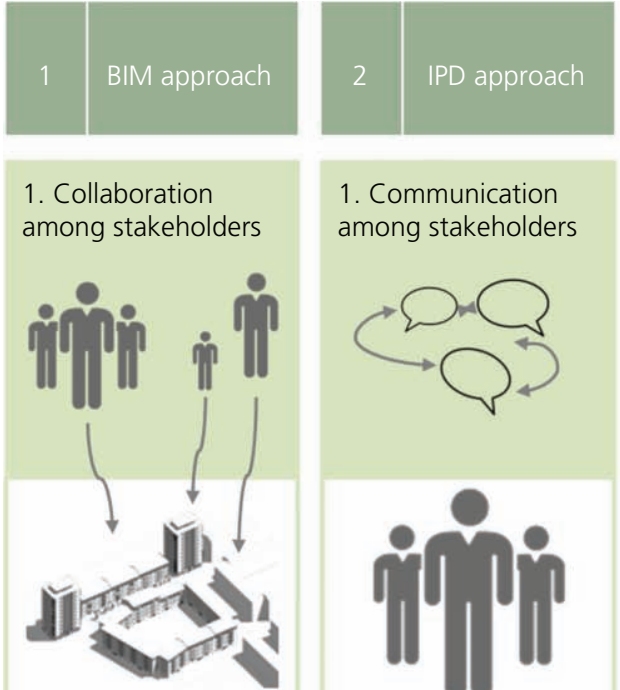

2. Continuous update (parametrisable elements)

3. Change reduction

4. Cost reduction
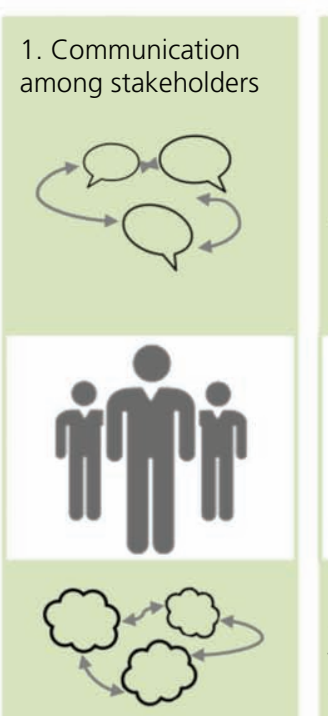

2. Knowledge sharing among stakeholders

3. Setting of objectives (reach consensus)

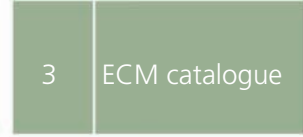

1. District- and buildinglevel measures

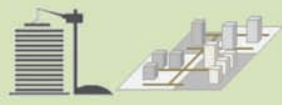
on DPIs

3. Optimisation based on calculation results

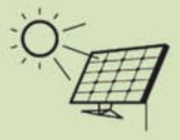

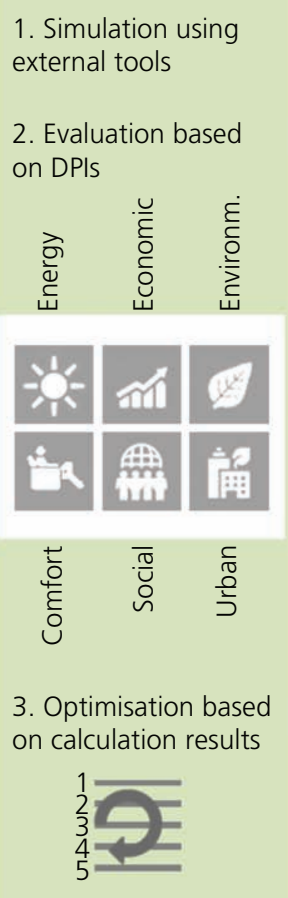
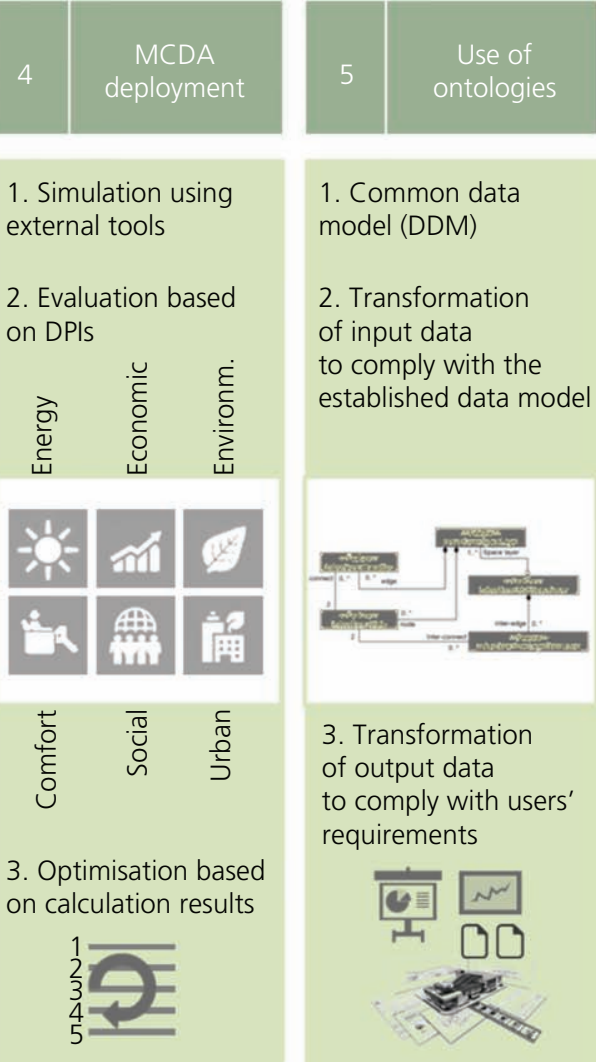

1. Common data model (DDM)

2. Transformation of input data to comply with the established data model

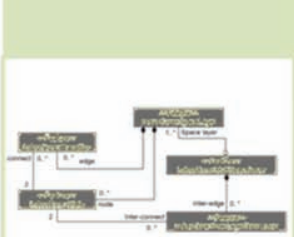

3. Transformation of output data to comply with users' requirements

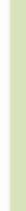

Figure 1. Five main pillars of the OptEEmAL solution. BIM, building information modelling; MCDA, multi-criteria decision analysis

energy prices, socio-economic data etc.) and configuration data (project description, IPD group, energy systems etc.).

From the data representation point of view (pillars 1 and 5), requirements have been identified for the definition of the ontology used to generate the OptEEmAL DDM (OptEEmAL Consortium, 2016d). The DDM has to integrate all the data needed to perform a refurbishment analysis of buildings within a district, including building data, district data, contextual data, DPIs, intermediate results and targets, barriers and boundaries delimiting the project assessment.

Related to the ECM catalogue (pillar 3), a set of requirements has been defined (OptEEmAL Consortium, 2016e) to determine the kind of information that the catalogue has to contain to feed properly the different steps within a project design, that way, the ECMs have to be stored in the catalogue and at which moments the catalogue is going to be queried to provide information to the modules/services of the OptEEmAL solution.

From a simulation point of view (pillar 4), the tools and methodologies for evaluating the DPIs required by the process implemented in the OptEEmAL platform towards the identification of the best retrofitting scenarios according to stakeholders' priorities for each design project have been investigated (OptEEmAL Consortium, 2016f). As a result, a set of requirements has been identified to guide the design of the OptEEmAL DPI calculation element of the platform, divided into two parts, building- and district-level calculation methodologies.

In the case of the optimisation process (pillar 4), the specification of a set of parameters that adequately represent the refurbishment plan, the barriers, boundaries and the stakeholders' priorities which aim to defining the optimum scenarios have been established (OptEEmAL Consortium, 2016g).

Finally, and in order to complete the analysis of requirements more related to the whole platform, different aspects have been analysed more deeply, comprising functional requirements and non-functional requirements such as performance, security, human-machine interaction, system management (configuration and interoperability) and data management.

The translation of all these requirements into a set of use cases has been necessary to define the high-level architecture of the OptEEmAL solution presented in the following subsection.

\subsection{High-level architecture of the OptEEmAL solution}

With the aim of fulfilling the requirements and functionality expected for the whole OptEEmAL system, a three-layer 
Smart Infrastructure and Construction

Volume 172 Issue 3
Software solution to design energy-

efficient retrofitting projects at district

scale

Martín-Toral, Serna-González, Álvarez-Díaz et al. architecture is envisaged and presented in Figure 2 (OptEEmAL Consortium, 2016h).

The application layer works as interaction point between the OptEEmAL platform and the user. It is used for inserting data and showing results and providing outputs, as well as for other interactions (viewing results, checking the progress of the processes, etc.).

The business logic layer contains the modules with the main functionalities of the platform - namely, the data insertion module, the data-management module (DMM), the simulation module, the optimisation module and the data exportation module. Moreover, this layer contains the communication logic layer that acts as the link among the different modules of the platform since it enables the communication between the data layer and the service layer. Details about these key components and their interaction with the application and data layers are presented in Section 3.1 and in the three process schemes of Figures 6-8.

Finally, the data layer represents the OptEEmAL data repository, which is composed of five different repositories: the BIM, CityGML, context, project and ECM repositories. The context,
BIM and CityGML repositories store information about the buildings and districts to refurbish. On the other hand, the project repository holds information about the refurbishment projects (e.g. the platform users and user's inputs, e.g. barriers, targets, boundaries and prioritisation criteria) and data generated within the platform such as DPIs, scenarios and simulation models (energy, economical, environmental etc.) automatically generated. The ECM repository contains the ECMs used to generate the refurbishment scenarios to be optimised by the OptEEmAL platform and also contains information about these ECMs to be exported in the final step.

In order to work properly, the OptEEmAL platform also needs to interoperate with other external existing services and tools needed to support and enhance part of the expected functionality to be offered mainly by the simulation module. These external tools comprise the following.

EnergyPlus. It is an energy analysis and thermal load simulation program. Based on a user's description of a building from the perspective of the building's physical makeup, associated mechanical systems and so on, the EnergyPlus

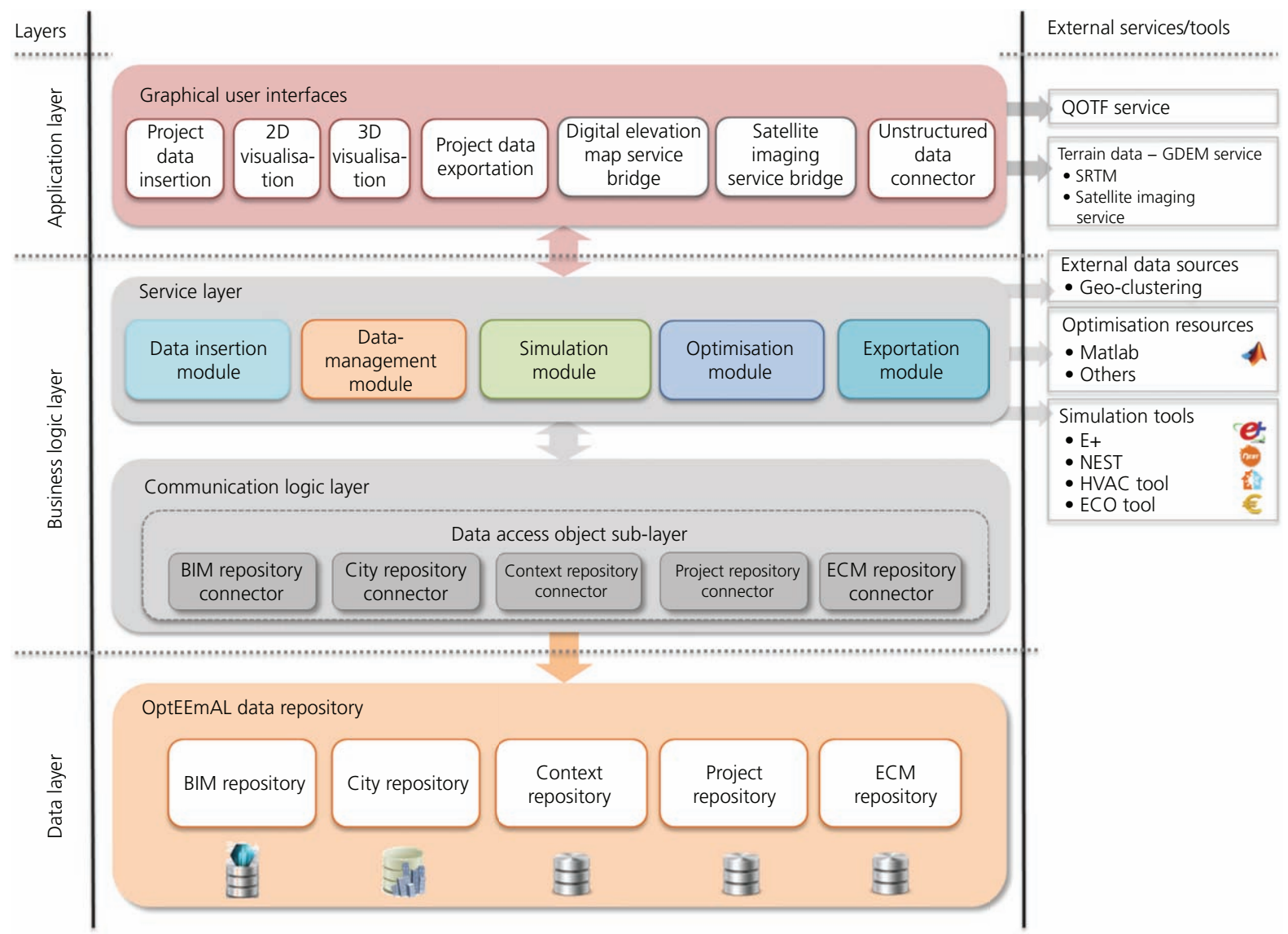

Figure 2. High-level architecture of the OptEEmAL platform. GDEM, global digital elevation model; HVAC, heating, ventilation and airconditioning; SRTM, Shuttle Radar Topography Mission; QOTF, query on the fly unstructured data service 


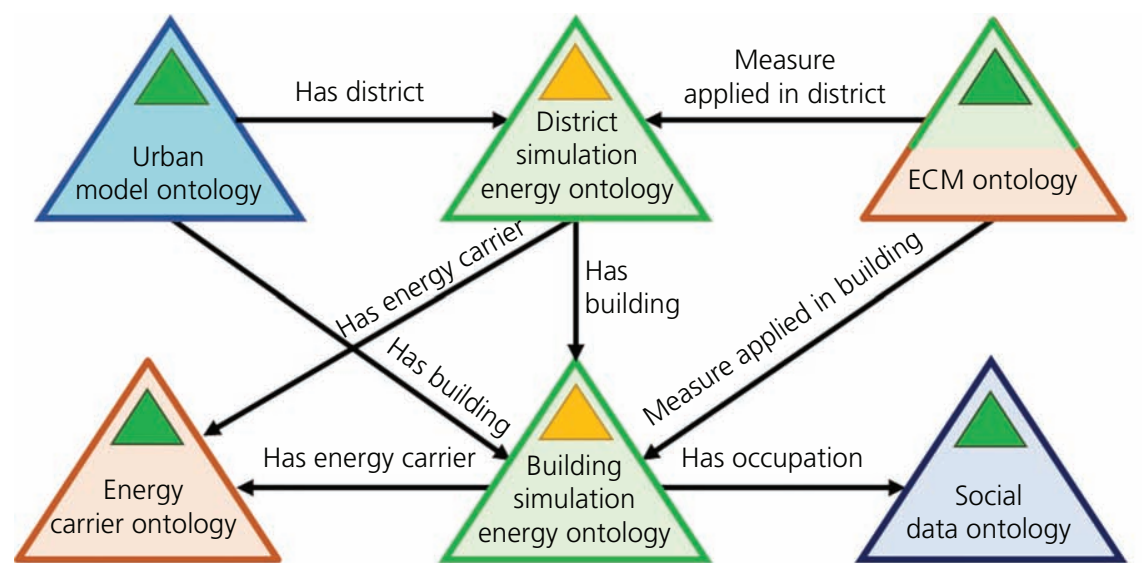

Reused ontologies

Figure 3. Ontologies included in the DDM to represent the data of the district

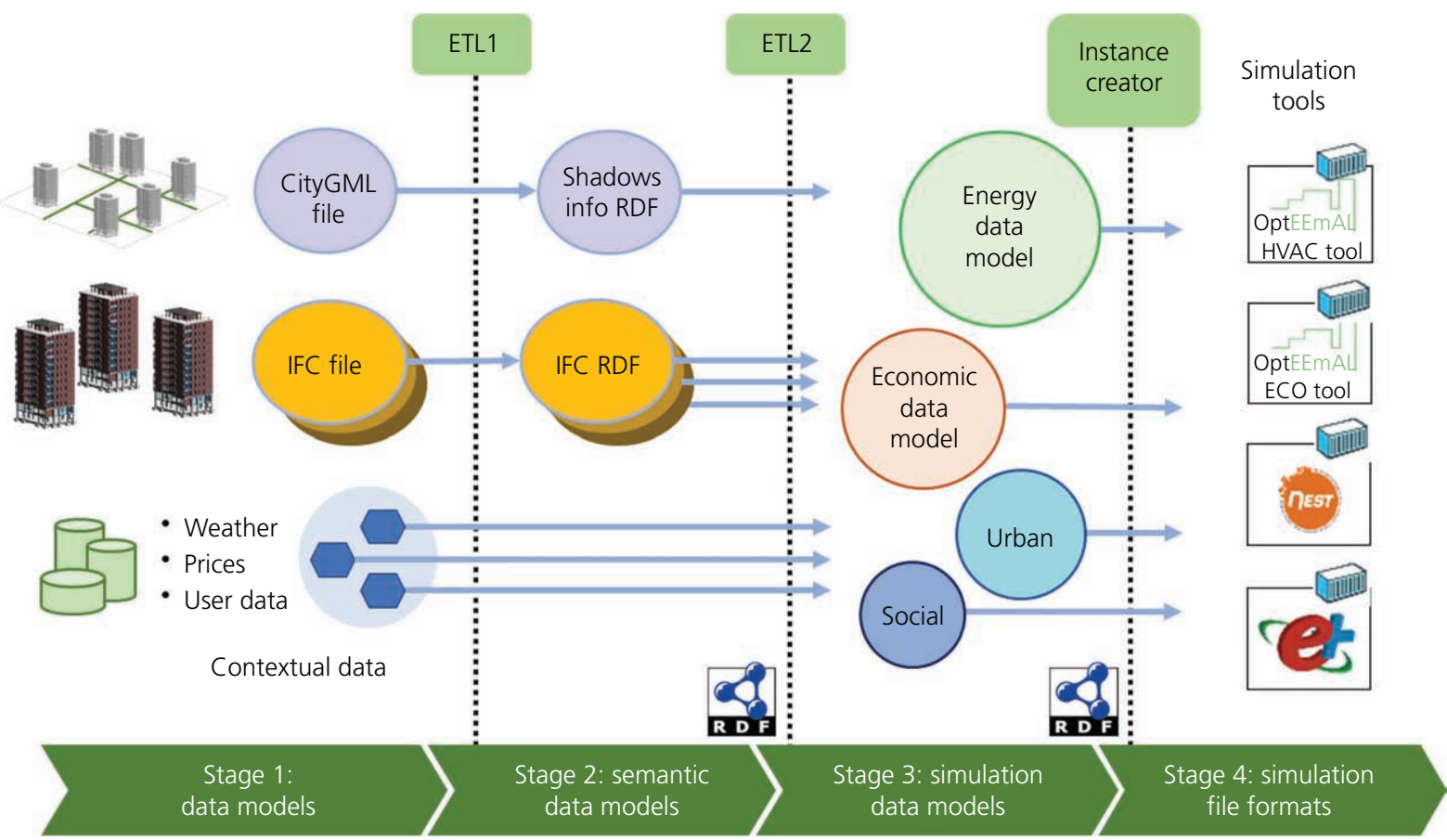

Figure 4. Transformations carried out in the DMM

software program is able to calculate the heating and cooling loads necessary to maintain thermal control set points; conditions throughout a secondary heating, ventilation and air-conditioning (HVAC) system and coil loads; and the energy consumption of primary plant equipment as well as many other simulation details that are necessary to verify that the simulation is performing as the actual building would.

- NEST. This is used within OptEEmAL for life-cycle and social DPI calculation. NEST is a plug-in for the SketchUp software program based on the life-cycle analysis methodology. It allows, from 3D modelling of the area, impact assessment and comparison of development scenarios.
- Matlab runtime compiler. The Matlab runtime compiler enables developers to share Matlab scripts into standalone applications. Using this solution, it is possible to pack M-Files as Java libraries used by the DPI computation process. The M-Files are organised into Java classes, and each Matlab function is provided as Java methods.

- Terrain data access. In order to provide the user with a userfriendly view of the district, the terrain geometry mapped with satellite images is displayed around the district location. These data are obtained from open-source third-party services such as advanced spacebone thermal emission and reflection radiometer global digital elevation map (Aster G DEM) and 


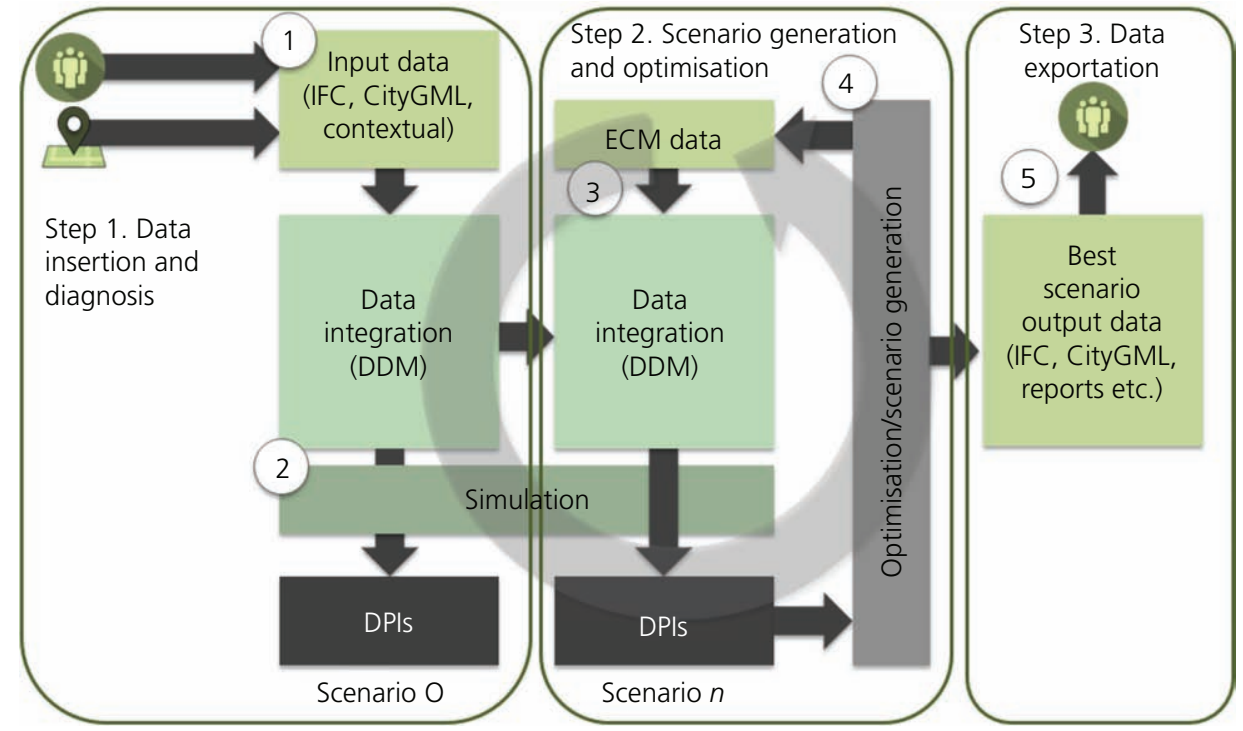

Figure 5. Three main processes of the OptEEmAL workflow

Shuttle Radar Topography Mission for the terrain geometry and from OpenStreetMap and/or similar satellite imaging services for the satellite images.

Other ad-hoc implementations have been developed to cover the calculation of specific DPIs -for example the Eco tool, for the calculation of economic indicators, and the HVAC tool (De Tommasi et al., 2018), for the simulation of the active energy systems of the building/district.

\subsection{DDM for data representation}

As previously mentioned, the interoperability of an information technology solution is ensured by using well-known communication procedures, common data models, and standardised interface definitions. Regarding data models, in OptEEmAL, the DDM is used as a means to represent, in a common manner, all the input data (BIM/CityGML models, contextual data, inputs from the users etc.) necessary for the operation of the platform. For this, it is necessary to carry out processes to collect, integrate and transform the input data into this common model. Through the DDM, the interoperability and understanding of the information to be exchanged among modules, components, services and external tools is ensured.

The DDM is conceived as an ontology-based framework for district information representation that enables the intertwining of standardised data models (e.g. CityGML and IFC) with ontologies in domains (energy, social, environment, comfort, urban morphology and economic) related to building energy efficiency at the district level (OptEEmAL Consortium, 2016d). An ontology can be defined as 'a formal and explicit specification of a shared conceptualisation of a domain of interest' (Gruber, 1993: p. 1). This way, the DDM provides a semantically integrated data model where different data about geometry, materials, equipment and costs among others, at the building and urban scales, are represented according to the ontology that encompasses each particular domain. Among the advantages, this flexible semantic data model approach enables new domains to be included through their corresponding ontology without altering the existing data. In addition, it facilitates a comprehension of the data through their semantics. This is very useful for those who have to map the data of the DDM to the models used as an input in the different simulation tools necessary to calculate the optimised retrofitting scenarios. In this context, semantic data models are representations of the data models in the Resource Description Framework (RDF) format.

The DDM includes the following six ontologies for representing the data of the district (Figure 3).

- Urban data model. This model represents the data about the relations between buildings, weather, placement, population, total surface of buildings and relations to other data models (e.g. which district energy system is a building connected to).

- Building energy data model. This model represents the data necessary to carry out energy simulations of buildings. It includes the geometry of the building, material properties, building energy systems and so on.

- District energy data model. This model represents the data necessary to carry out energy simulations at the district level. Essentially, it includes the data of active systems at the district scale.

- Energy carrier data model. This model represents the data of energy carriers that can be selected for a project. Basically, it includes energy carrier costs.

- Social data model. This model represents the social data of a district. It includes the number of inhabitants and their income, required for the calculation of social indicators. 


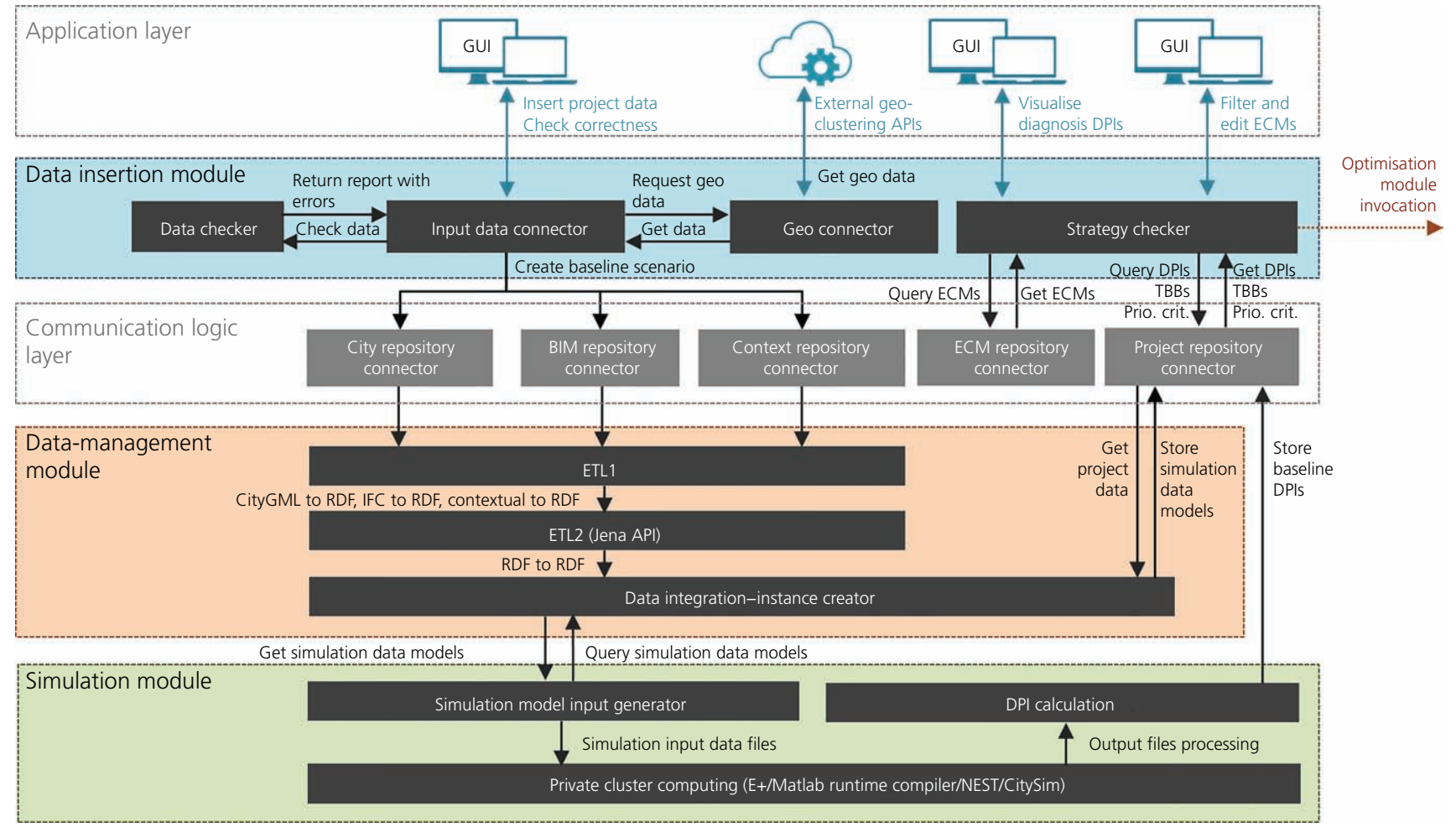

Figure 6. Data insertion and diagnosis process scheme. APIs, application programming interfaces; ETL, extract, transform and load; GUI, graphical user interface; Prio. crit., prioritisation criteria; RDF, Resource Description Framework; TBBs, tarjets, boundaries and barriers

- ECM data model. This model represents the data about the ECMs at the building or district scale that are needed for generating energy-efficient retrofitting scenarios.

Most of these ontologies have not been created from scratch. They include parts of one or more of the existing ones, which are complemented with new terms and relations to meet the specific needs of each particular domain. The reuse of existing ontologies as much as possible is considered a good practice and also a challenge to ease interoperability (Lonsdale et al., 2010; Simperl, 2009). For example, the urban data model, energy carrier data model, social data model and ECM data model include terms and parts of the scheme of the Semanco ontology (Madrazo et al., 2012). This ontology contains concepts and properties related to the domain of urban energy models at different scales. Regarding the case of the building and district energy data models, the SimModel ontology (Pauwels et al., 2014) based on the SimModel specification (O’Donnell et al., 2011) has been almost completely reused.

The DDM is managed in the OptEEmAL platform by a module called DMM, implemented using Semantic Web technologies. This module is intended to carry out the different stages required to transform and integrate the necessary data to generate the DDM. The module includes two components: $(a)$ the DDM manager and $(b)$ the instance creator. Both components are developed in Java and implemented under the Semantic Web technology approach.

The DDM manager provides the necessary functionalities to carry out the corresponding data transformation and integration processes. For their implementation, Semantic Web technologies have been used since they facilitate finding and establishing relations between the concepts of source and target ontologies. This way, through these relations. it is possible to integrate the data from different sources to a data model generated according to a target domain ontology (e.g. energy simulation domain represented by the SimModel ontology).

The transformation and integration processes are carried out as extract, transform and load (ETL) processes. They are identified as ETL1 and ETL2 correspondingly (see Figure 4). The ETL1 process transforms the input data models (e.g. IFC and CityGML) into semantic data models (RDF models), represented according to different data schemas (e.g. ifcOWL ontology). The ETL2 process integrates the data resulting from the ETL1 process where semantic data models are transformed into simulation data models (e.g. RDF models represented according to the Web Ontology Language version of the SimModel data schema). One of the advantages of this approach is that the transformation rules for integrating the data can be maintained and extended by the community. This is possible since the transformations have been 
Smart Infrastructure and Construction Volume 172 Issue 3
Software solution to design energyefficient retrofitting projects at district scale

Martín-Toral, Serna-González, Álvarez-Díaz et al.

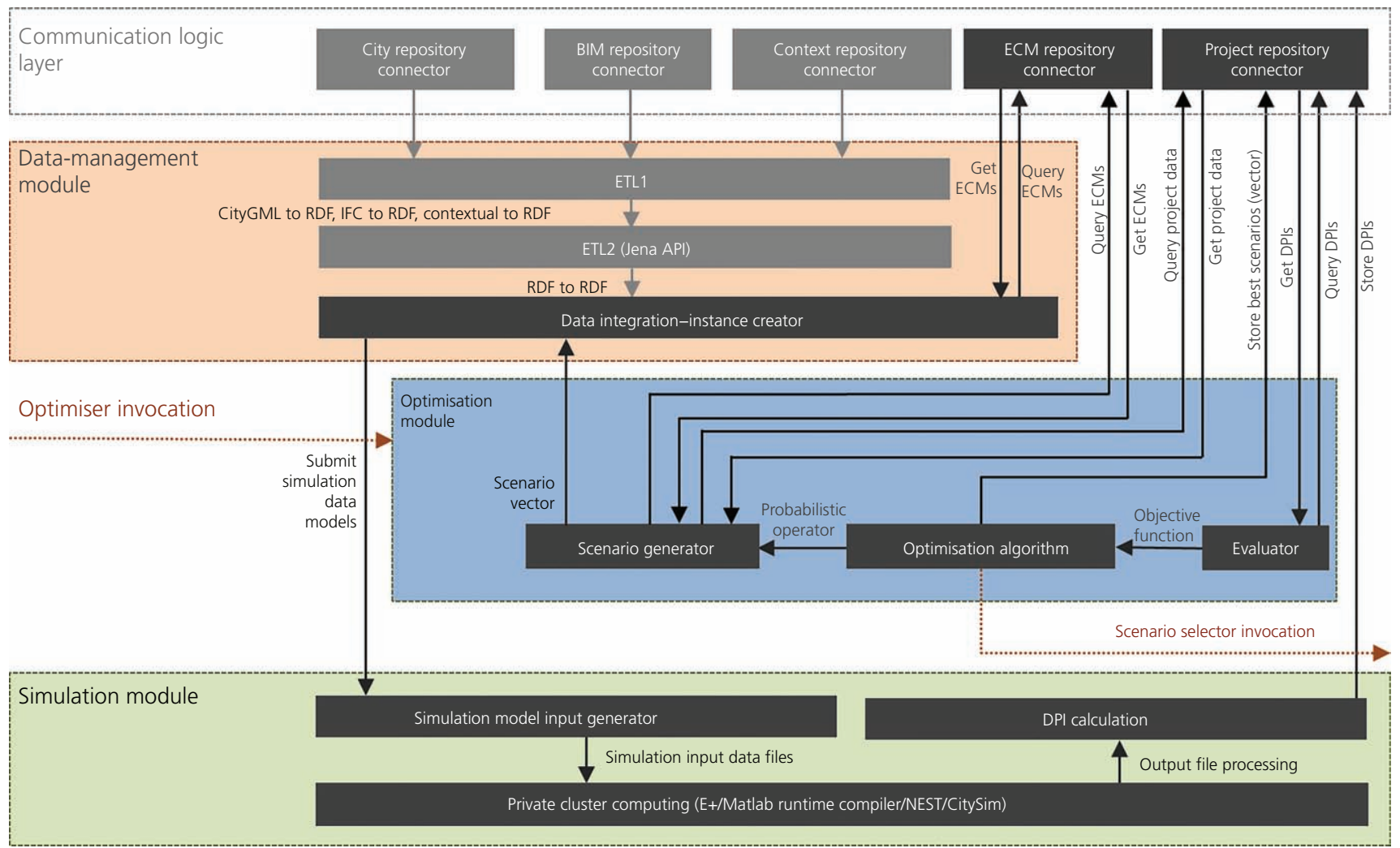

Figure 7. Scenario generation and optimisation process scheme

coded in a declarative language such as SPARQL instead of using procedural programming (Sicilia and Costa, 2017).

Another process carried out in the DDM manager is the integration of the data of active building energy systems into simulation data models, at the building and district scales. This information comes from possible existing combinations of active systems chosen by the end users of the platform through a questionnaire.

Finally, the simulation module (presented in Figure 2) invokes the model input file generator process to create instances of simulation models from the simulation data models generated in the DDM manager. An instance of simulation model is a set of data that fulfil the input data requirements of a specific simulation tool (e.g. EnergyPlus requires the input data to be in Input Data File Format).

The second component of the DDM, the instance creator, is aimed at applying ECMs in those simulation data models generated by the DDM manager in an automated way. ECMs to be applied are selected from an ECM catalogue. In this catalogue, the measures are described in RDF format - a World Wide Web Consortium specification - and according to the SimModel ontology. The selection is indicated by a component of the platform responsible for the optimisation of the design solution, in the simulation models.

\section{Platform design, implementation and deployment}

In the platform design stage, the high-level architecture has been taken into account and the modules have been finely described, explaining their main components with the functionalities related and the process schemes that identify the workflow followed in the platform and also the information exchanged between the components (OptEEmAL Consortium, 2016h).

Once the platform has been designed, the next steps are the implementation and the deployment of the platform. All these steps are explained in the following subsections.

\subsection{Component diagrams and process schemes}

According to the workflow generated as part of the requirements definition, the functionality of the platform can be divided into three main processes (Figure 5), where interactions among modules of the high-level architecture and their components are explained. The first and the last processes include user interaction, whereas the second one is a black box towards the user.

(a) Data insertion and diagnosis process. In this first process, all the required information to run the OptEEmAL process is gathered, checked and stored; the baseline of the district is also calculated. At this point, the users should have been able to set adequately some objectives to be pursued within their 


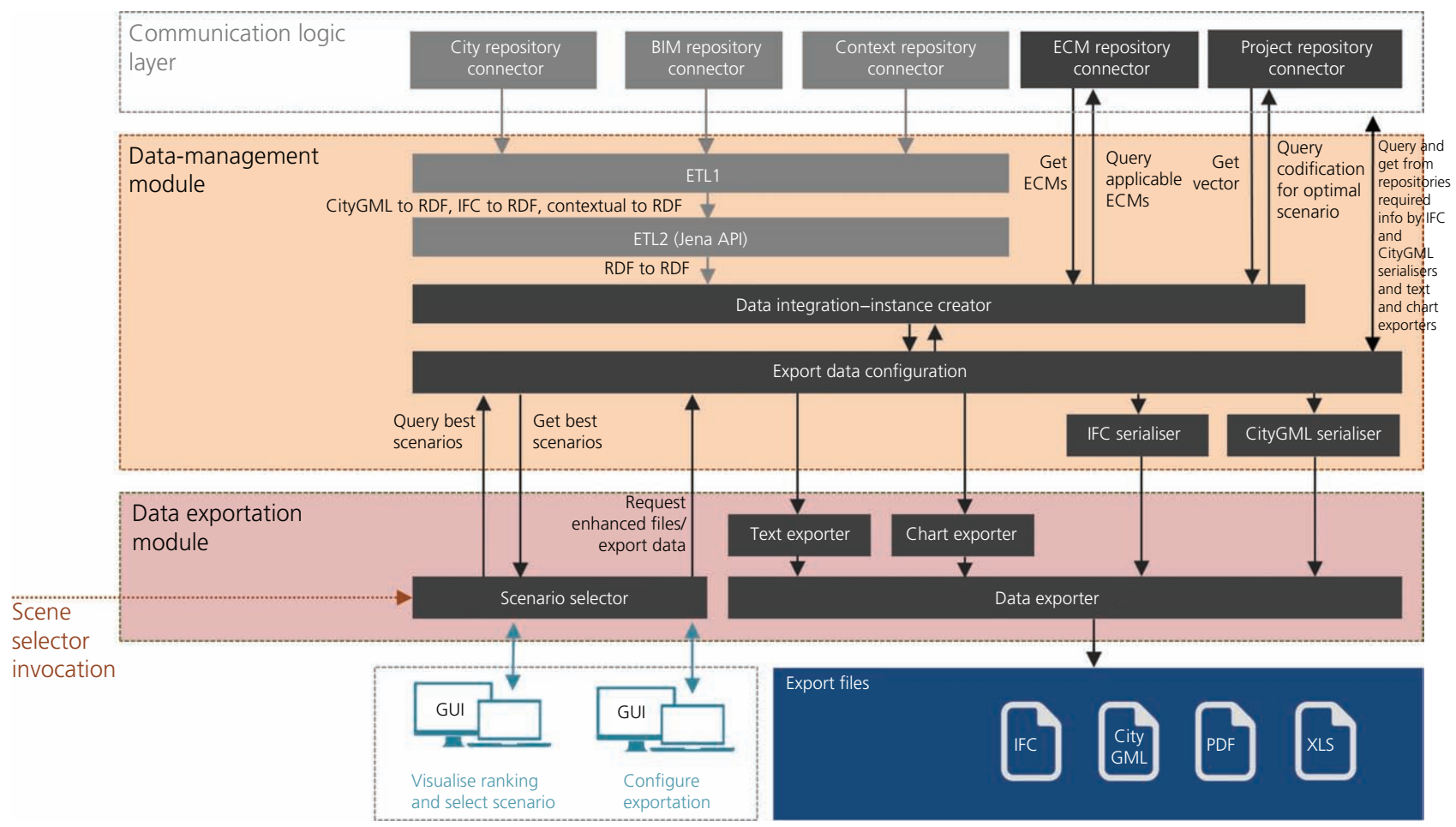

Figure 8. Data exportation process scheme

retrofitting project according to their baseline conditions and are ready to launch the optimisation process.

(b) Scenario generation and optimisation process. An iterative process is performed at this step, which will run during several loops until the optimal solution is found. It consists of the following steps: scenarios are created (based on combinations of ECMs), simulation models are generated and calculated, the results of the scenarios are weighted and evaluated and the process starts again until the optimal solution has been reached.

(c) Data exportation process. The main objective of this step is for the users to select the optimal scenario from the ones offered by the platform and the retrieval of information related to this scenario and the process followed in different file formats.

Each of these processes involves a set of modules. The process schemes show the different components that constitute each module and the relationship between these components. They are explained in the following.

\subsubsection{Data insertion and diagnosis process}

This process, presented in Figure 6, provides as an output of all the data needed to be introduced into the optimisation module. To this end, through the data insertion module, the user can introduce all the required data (CityGML of the district, IFC of the building in the district, targets, boundaries and barriers, as well as prioritisation criteria) inserted through the input data connector component. Then, these data are checked (data checker component) and complemented with information coming from external geo-clustering services (geo-connector component).

The data inserted by the users are checked for integrity and correctness in the data checker component that is based on a specifically developed checking tool. This tool has three different checking operations (Lilis et al., 2018): consistency check (IFC4 schema compatibility), completeness check (the required input data for the building energy performance simulation model by checking rules (Giannakis et al., 2019): space boundary, material properties and space conditions rules) and correctness check (geometric error detection).

After having been checked, all these data are stored in the corresponding repositories through the appropriate connector of the communication logic layer.

Once the information is stored in the repository, the DDM (presented in Section 2.3) maps the information in order to create one instance of the baseline scenario. The simulation data models generated by the data integration-instance creator component are stored in the project repository.

This information is retrieved later by the simulation module (simulation module input generator component) (Giannakis et al., 
Smart Infrastructure and Construction

Volume 172 Issue 3
Software solution to design energy-

efficient retrofitting projects at district

scale

Martín-Toral, Serna-González, Álvarez-Díaz et al.
2017), which will be in charge of configuring the simulation files and launching the simulation tools (private cluster computing component). With the result of this process, the DPI calculation component calculates diagnosis DPIs - that is, DPIs representing the initial conditions of the district in terms of energy, urban, social, environmental and economic impact. These diagnosis DPIs are stored in the project repository.

The last step in this process requires user interaction to validate the generated information. The results from the DPIs are extracted from the project repository and shown to the user along with other information of the baseline scenario (data insertion module), who, taking into account these results, could reconsider the choices that they have made with regard to their objectives. With this revised list of targets, boundaries and barriers, the ECM catalogue is queried to provide the user with the list of applicable ECMs filtered according to their objectives. Through a specific graphical user interface (GUI), the user can discard the ECMs that they do not want to apply in their district, or edit the characteristics of the applicable ones proposed by the platform (strategy checker component). This information will configure the optimiser input data to be used in the next process.

\subsubsection{Scenario generation and optimisation process}

This process (see Figure 7) represents the core element of the platform, where scenarios are generated from different combinations of ECMs and the DPIs are calculated by launching simulations with external tools. These results are evaluated to be able to have as an outcome a series of optimised scenarios and the data generated along this process (García-Fuentes et al., 2018; Hernández et al., 2017).

The optimiser input data generated in the previous process are introduced into the optimisation module (scenario generator component), which is in charge of generating scenarios by means of combining the applicable ECMs in the retrofitting project with a certain intelligence: first by considering which of the ECMs cannot be applied at the same time and then by applying a multiobjective harmony search algorithm. This algorithm attempts to optimise simultaneously two (possibly conflicting) objective functions: cost and benefit, which, in the case of OptEEmAL, are calculated based on the DPI results and considering the weights assigned to them by the users (prioritisation criteria). This way, instead of finding a single solution to the problem, it obtains a set of good compromises or trade-offs called the Pareto optimal set (Manjarres et al., 2017; OptEEmAL Consortium, 2018a).

With the application of this harmony search, a series of 50 scenario vectors per iteration are obtained as a result. Each scenario vector identifies the ECMs at the building or district level that are applied in each of the scenarios. This information is mapped in the DMM (data integration-instance creator component) and is complemented with information coming from the ECM database to configure the simulation data models in each of the loops.
Once the simulation data models have been created, the simulation module (simulation module input generator component) launches the simulation tools (private cluster computing component) (Katsigarakis et al., 2019) and the DPI calculation component in order to calculate the simulation DPIs, which will be directed to the DMM to be stored in the project repository.

Once the DPIs are stored, these can be retrieved by the optimisation module (evaluator component) (García-Fuentes et al., 2018) in order to have two single, understandable and easy-to-handle values or grades for each scenario to be ranked in by the optimisation module: cost and benefit values. With the result of the objective function, either the optimisation module (optimisation algorithm component) will generate more combination rules and will continue the iterative process or the stopping criteria will be met and the optimiser output data will be generated and stored in OptEEmAL repositories.

\subsubsection{Data exportation process}

The last stage carried out in the platform is the data exportation process (see Figure 8), where the main objective is to process the information generated in the previous stage in order to obtain exportable information that is relevant for the user to execute their retrofitting project.

The process starts in the data exportation module, where the user can visualise through a GUI the ranking of scenarios generated in the optimisation process. Afterwards, through a different GUI and another component (scenario selector component), they are able to select their desired scenario.

This selection will launch the export data configurator component (inside the DMM), which will be connected to the different repositories to extract the necessary information to be exported as indicated by the user. These data will be processed through several components (IFC serialiser, CityGML serialiser in the DMM and text exporter and chart exporter in the data exportation module) to end up in the data exporter component, which will in the end enable the user to export the files with the information: IFC, CityGML and XLS.

\subsection{Implementation and deployment}

The OptEEmAL platform is composed of different modules and components described in the previous sections. In order to carry out their functionalities, the modules need to communicate among each other and with external tools and services. The module dependencies have been analysed, and the logical interfaces between modules have been defined. It is important to highlight that the modules and the repositories of the platform have been developed by different entities, so the definition and development of the interfaces were essential steps in the implementation of the platform.

Red Hat JBoss Fuse has been used as an enterprise service bus (OptEEmAL Consortium, 2018b), whose role within the OptEEmAL platform is to synchronise different and asynchronous modules deployed on several environments and to have a base control of these. This is an open-source integration framework 
Smart Infrastructure and Construction

Volume 172 Issue 3
Software solution to design energy-

efficient retrofitting projects at district

scale

Martín-Toral, Serna-González, Álvarez-Díaz et al. based on Apache Camel, and it is a distributed integration platform that allows the integration of services, microservices and application components. This enables delocalisation of the different modules and repositories of the platform.

From a deployment point of view, Figure 9 shows the physical distribution of the different modules and repositories. As shown in the figure, the different modules and repositories are geographically distributed in three different premises and locations. In that sense, security and reliability in the communications are needed and guaranteed by the enterprise service bus.

The repositories can be accessed through APIs in a remote way. Moreover, queues are used in order to send files that are too large to be managed by the APIs.

\subsection{Validation of the OptEEmAL prototype}

In this section, a summary of the monitoring process of the OptEEmAL prototype is presented as a way of analysing the performance of the solution during the project execution and particularly during the demonstration and validation stage of the platform.

In order to ensure the reliability, accuracy and final usability of the OptEEmAL solution, the validation of the developed platform in different operational environments has been demonstrated in the final stages of the project. The validation and demonstration of this platform on technical and societal levels appears as a key part of the project, as it aims to show how the platform is ready to be used, useful and relevant to designing energy-efficient district retrofitting plans offering accurate results and fulfilling end-users' requirements. With this aim, the OptEEmAL platform has been validated in three different technology readiness levels (TRLs), from TRL5 to TRL7.

A summary of the validation methodology can be seen in Table 1, and it is explained in the following.

TRL5 (technology validation in a relevant environment) was firstly demonstrated, where the modules and components of the platform were integrated and deployed to validate the technology in relevant environments. In this case, the global functioning of the platform was tested using a fictive example of a district in the city of Santiago de Compostela (Spain) with two fictive (and simple) buildings. This example was called Demo4.

In order to ensure the integration and interoperability of all the components, services and repositories making up the first OptEEmAL prototype, the objective of Demo4 validation was to guarantee the communication and understanding of all these elements geographically distributed (as shown in Figure 9) and managed by different developers. Moreover, in this case, the number of possible solutions is limited, so it is the perfect case to validate the precision of the DPI results obtained and the operation of the optimisation process. Following this objective, a set of end-to-end tests were defined and run for Demo4 to demonstrate complete actions launched by an end user and coherent results were obtained.

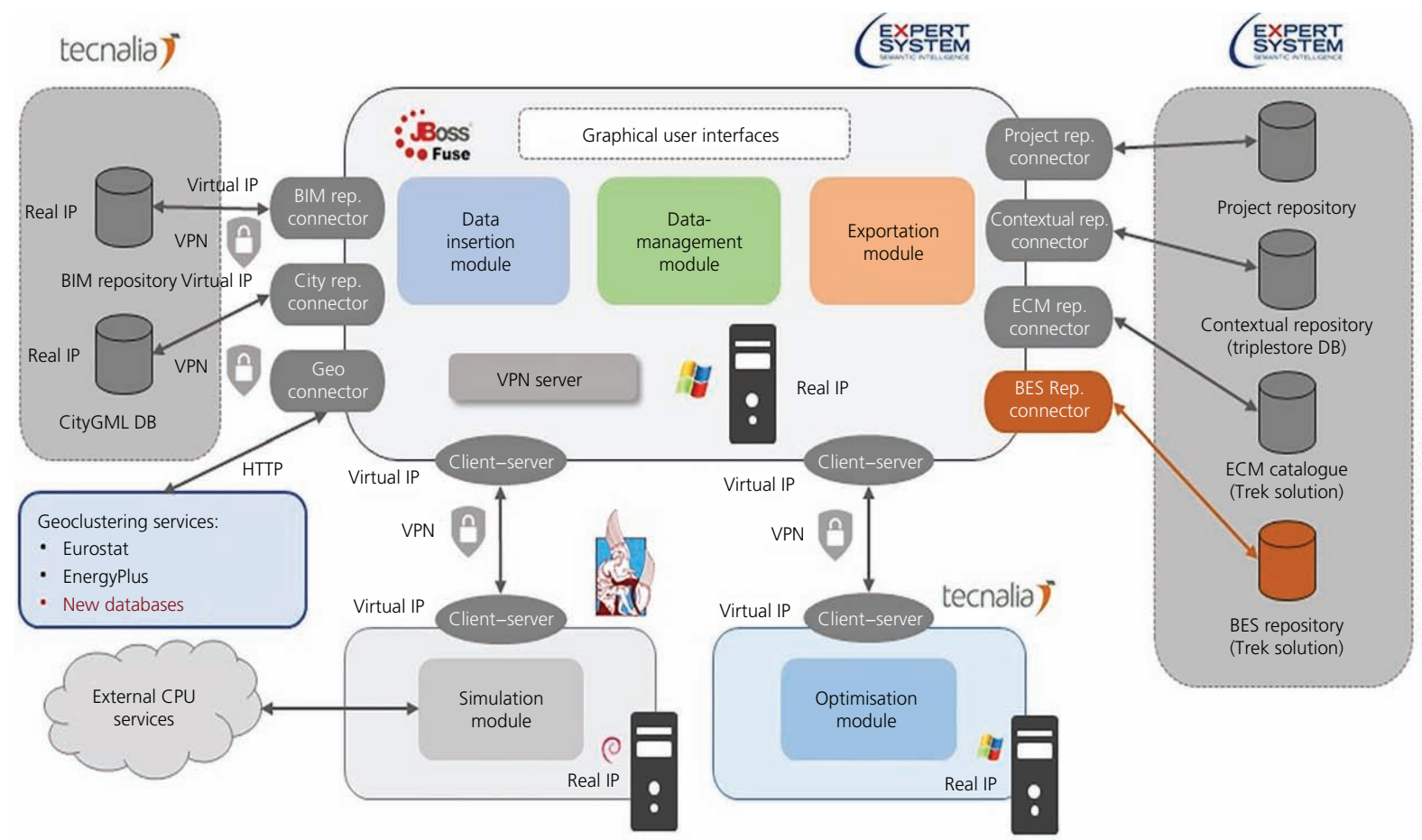

Figure 9. Deployment physical scheme. BES, building energy systems; CPU, central processing unit; DB, database; HTTP, hypertext transfer protocol; IP, Internet protocol; rep., repository; VPN, virtual private network 
Smart Infrastructure and Construction

Volume 172 Issue 3
Software solution to design energy-

efficient retrofitting projects at district

scale

Martín-Toral, Serna-González, Álvarez-Díaz et al.

Table 1. Summary of the validation methodology

\begin{tabular}{|c|c|c|c|}
\hline & Demo case & Validation objective & Validation method \\
\hline TRL5 & Demonstration site created ad hoc: Demo4 & $\begin{array}{l}\text { Modules correctly } \\
\text { integrated } \\
\text { Results are correct and } \\
\text { accurate } \\
\text { Optimisation process } \\
\text { converges fast enough }\end{array}$ & $\begin{array}{l}\text { Comparison with DPI results calculated by } \\
\text { other tools: EnergyPlus, Excel files, Matlab } \\
\text { scripts and so on }\end{array}$ \\
\hline TRL6 & $\begin{array}{l}\text { Demonstration site with existing/performed district } \\
\text { retrofitting plans: (a) Cuatro de Marzo district in Valladolid, } \\
\text { (b) Mogel district in Eibar and (c) Polhem district in Lund } \\
\text { Data available for these pilots }\end{array}$ & $\begin{array}{l}\text { Validation in a real } \\
\text { environment } \\
\text { Results are accurate and } \\
\text { similar to the business-as- } \\
\text { usual process } \\
\text { Testing of time efficiency } \\
\text { Checking of relevance for } \\
\text { users }\end{array}$ & $\begin{array}{l}\text { Comparison with results obtained after a } \\
\text { real evaluation and a real retrofitting plan } \\
\text { have been executed }\end{array}$ \\
\hline TRL7 & $\begin{array}{l}\text { Demonstration sites located in two different climatic zones: } \\
\text { (a) Txomin Enea district in San Sebastián and (b) San } \\
\text { Bartolomeo district in Trento } \\
\text { Data needed have been collected }\end{array}$ & $\begin{array}{l}\text { Validation in a real and } \\
\text { uncontrolled environment } \\
\text { Testing of usability and } \\
\text { reliability }\end{array}$ & $\begin{array}{l}\text { Testing from the beginning to the end of } \\
\text { the process } \\
\text { Assessing the adequacy of the results }\end{array}$ \\
\hline
\end{tabular}

For this validation, a meticulous process was followed. Firstly, the starting point was defined: the generation of the demo and the approach of the problem to be solved (ECMs to be applied). On the one hand, the problem was simple enough to be able to perform the DPI calculations also in a semi-automatic way (out of the platform) to be able to compare the results. On the other hand, they added all the possible elements to extend the object of study without making the problem too complex. For the calculation results to be compared and analysed, EnergyPlus, Excel files, Matlab scripts and other tools were used.

In this validation, problems and incoherencies were detected and corrected in different steps: bugs in some modules, incoherencies in data for different modules and so on.

After this validation for a fictive case study, a step forward to the demonstration in TRL6 (platform prototype demonstration in relevant environment) was performed (OptEEmAL Consortium, 2019a). In this case, the tested project was selected among projects in which existing/performed district retrofitting plans had been launched. Due to the complexity of the processes developed within the platform and in order to ensure the accuracy of the results obtained, finally three case studies were tested using the OptEEmAL platform, covering three different climatic areas and different building energy systems: Cuatro de Marzo district in Valladolid (Spain - Mediterranean climatic zone), Mogel district in Eibar (Spain - Atlantic climatic zone) and Polhem district in Lund (Sweden - Nordic climatic zone).

The purpose of this TRL was to demonstrate the correct and accurate functioning of the platform prototype in real districts where real retrofitting actions had been previously implemented. It was of particular importance to validate that the platform has fulfilled its technical requirements (correct calculations, relevant calculation time, useful GUIs etc.) and answered end-user needs (provide relevant, accurate and useful information in a time-efficient process). All this information obtained from the platform was later compared with the existing and available information of the real retrofitting plans in order to fine-tune the OptEEmAL prototype.

Under this scope, a detailed analysis and comparison of the data provided by OptEEmAL and those data coming from the R2Cities project (R2Cities Consortium, 2019) was developed for the Cuatro de Marzo district (and also for the other two case studies mentioned before). Incoherencies were detected and corrected at different levels in different functionalities of the platform - for example

normalisation

- of DPIs related to units

- adjustment of the energy consumption considering renewable energy production (energy that does not need to be consumed from the grid but comes from renewable installation)

- coherency regarding DPI units when comparing the baseline and scenario calculations

- incorrect equation calculations

- predefined weighting schemes not well configured in the GUI

- indicated/introduced boundary for the investment was too high, affecting the normalisation of the economic cost of the interventions

- identification of different data sources used in the HVAC tool and $\mathrm{E}+$ simulation tool for Mogel district, affecting

- internal gains

- daylight control

- heating set point of thermostats

- infiltration classes

- occupiable/unoccupiable spaces

- boiler efficiency. 
Smart Infrastructure and Construction

Volume 172 issue 3
Software solution to design energy-

efficient retrofitting projects at district

scale

Martín-Toral, Serna-González, Álvarez-Díaz et al.
An exhaustive analysis of all of these incoherencies was executed by the responsible technical developer in order to find the reason for the problem and to apply the best amendment to guarantee the accuracy of the prototype.

Once the OptEEmAL platform was fine-tuned in TRL6, the demonstration of the platform in TRL7 (platform ready for demonstration in an operational environment) was launched (OptEEmAL Consortium, 2019b).

The objective of the assessment in TRL7 is to demonstrate the usability and reliability of the prototype when it is used in new district locations and the fact that it adequately follows an IPD approach. This IPD approach has to guarantee the collaboration and implication of all the stakeholders in the different steps of a project elaboration. The OptEEmAL solution has been validated in TRL7 for two demonstration sites located in two different climatic zones and with different pre-OptEEmAL building energy systems: Txomin Enea district in San Sebastián (Spain - Atlantic climatic zone) and San Bartolomeo district in Trento (Italy - Mediterranean/Continental climatic zone).

The validation of the OptEEmAL prototype in TRL7 covered all the steps, even in the elaboration of all the information that was fed to the platform. In that sense, IFC and CityGML files were created ad hoc, following the OptEEmAL IFC and CityGML guidelines (Giannakis et al., 2019), for demonstrating the prototype. As a result of the OptEEmAL prototype execution, the design of an 'optimal' refurbishment plan, according to the targets, boundaries and barriers specified by the IPD group, is obtained. Thus, the results provided by the platform in the form of cost-benefit (Pareto front) should help the owner of the project and other involved stakeholders to make decisions regarding a possible real execution of the refurbishment plan. Moreover, the IPD group counts on all the data generated by OptEEmAL to execute the real project (enhanced IFC files, DDM, baseline DPIs and scenario DPIs, ECMs to be applied, costs against benefits of the refurbishment actions etc.).

\section{Graphical user interfaces}

For the OptEEmAL platform, the GUI is a web/browser-based solution that facilitates the human-machine interface with the functionality offered by the design tool. The canvas interface is a website based on Hypertext Markup Language revision 5 and supported by a WebGL-based 3D visualisation environment.

The GUI is composed of different components.

- User data input module. This is responsible for collecting data inputs from the users - for example, the login information and project data such as the project name, description, CityGML and IFC files that will be used in the optimisation phase.

- Two-dimensional (2D) visualisation module. This module will provide the user with all necessary data and interactive graphical interface in the form of texts, charts, tables or similar representations.
- Three-dimensional visualisation module. A 3D representation of the district and buildings will be shown in this module.

- Data communication module. This module is responsible for data communication between the $2 \mathrm{D}$ and $3 \mathrm{D}$ visualisation modules.

- Third-party digital elevation map service communication module. This module acts as an interface to obtain from thirdparty services the information required by the $3 \mathrm{D}$ visualisation module to visualise the terrain geometry around the district.

- Third-party satellite imagery communication module. This module will act as an interface between the $3 \mathrm{D}$ visualisation module and the third-party satellite imaging services to obtain the district satellite images that will be shown on top of the terrain geometry.

- Unstructured data connector module. In this module, the users can search in the web for useful information related to the district to support the evaluation of the current scenario and its objective setting.

\subsection{Navigation scheme}

In this subsection, the navigation scheme followed by the OptEEmAL GUI is presented in 15 different steps. Figure 10 shows the site map of the OptEEmAL platform (OptEEmAL Consortium, 2016h).

The first page shown in the platform is the visitor overview with the login page for the platform users. From this point, the enduser interaction in the GUI is required in the next steps (steps $(a)-(l)$ are related to stage 1 (data insertion and diagnosis process), whereas steps $(m)-(o)$ are related to stage 3 (data exportation process)):

(a) create new project

(b) create a new IPD group

(c) insert CityGML and IFC files

(d) CityGML-BIM matching

(e) baseline energy systems

(f) insert contextual data

(g) ECMs

(h) heck strategies

(i) baseline performance

(j) insert targets and boundaries

(k) prioritisation criteria

(l) problem summary

(m) optimisation process

(n) select optimal scenario

(o) configure and export data.

After all the information required by the system is collected and verified, the necessary processes are launched to obtain the initial performance of the district. The results of the calculations are presented to the users who can modify the targets, boundaries, barriers and prioritisation criteria, taking into account the results of the baseline district evaluation and come back again after the optimisation process. After ECMs are shown to the users and are then selected or discarded by them, the scenario generation and 
Smart Infrastructure and Construction Volume 172 Issue 3
Software solution to design energy-

efficient retrofitting projects at district

scale

Martín-Toral, Serna-González, Álvarez-Díaz et al.

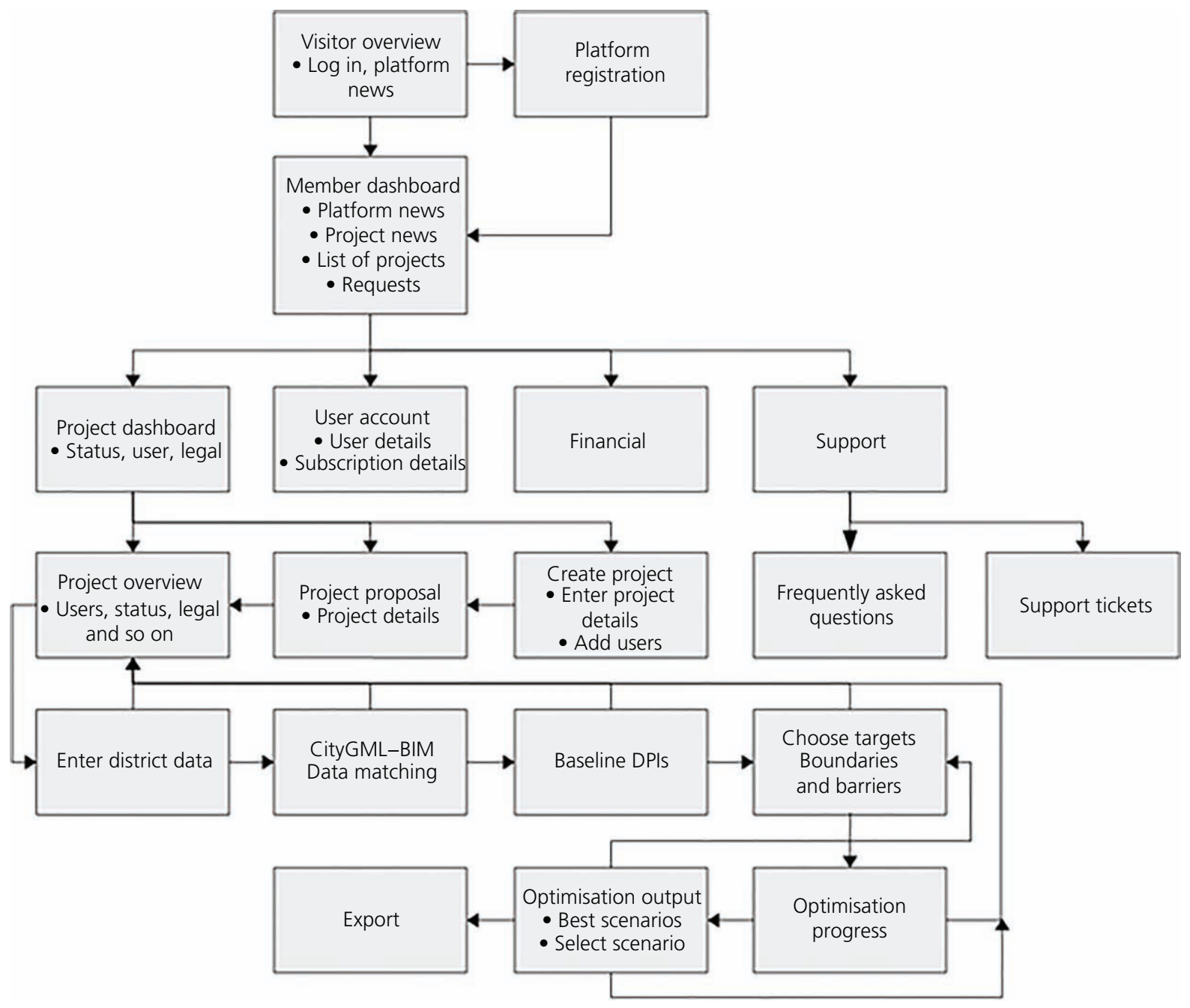

Figure 10. Site map of the OptEEmAL GUI as a website

optimisation phase takes place in the platform core. Finally, after the optimisation phase is finished, a number of best optimised scenarios for the district are shown to the users to select and export the best scenario for them. Once all the process is completed, and in case that the user does not find a proper scenario, they can go back again to the target, boundary and barrier selection phase in order to change or fine-tune their choices and to launch again the optimisation process.

\subsection{Example of use with a real case: Cuatro de Marzo district in Valladolid (Spain)}

As presented in Section 3.3, the platform has been tested and validated in different case studies or districts and for three different TRLs, from TRL5 to TRL7. One of them is Cuatro de Marzo district located in Valladolid (Spain), demonstrated for TRL6 (platform prototype demonstration in relevant environment).

Cuatro de Marzo district is located in the south of Valladolid, near the Pisuerga River (Figure 11).
The district has 189 residential buildings, linear blocks and a few towers. More detailed information is shown in Table 2.

For the Cuatro de Marzo case study, five residential buildings (two towers and three individual blocks - see Figure 12) have been tested for the retrofitting project. In this district, the information required and uploaded to the platform has been the following.

- Four IFC models (one IFC per block and one IFC used for the two towers, see Figure 13) and one CityGML model of the district. Figure 14 shows the interface where the user has to upload and check the models.

- BES-related information (with a questionnaire), shown in Figure 15.

- Biomass prices. Figure 16 shows the climate, energy and socio-economic data included in the contextual data interface with the biomass price data for this project.

- Targets and boundaries. Figure 17 shows the information completed for the Cuatro de Marzo project. 


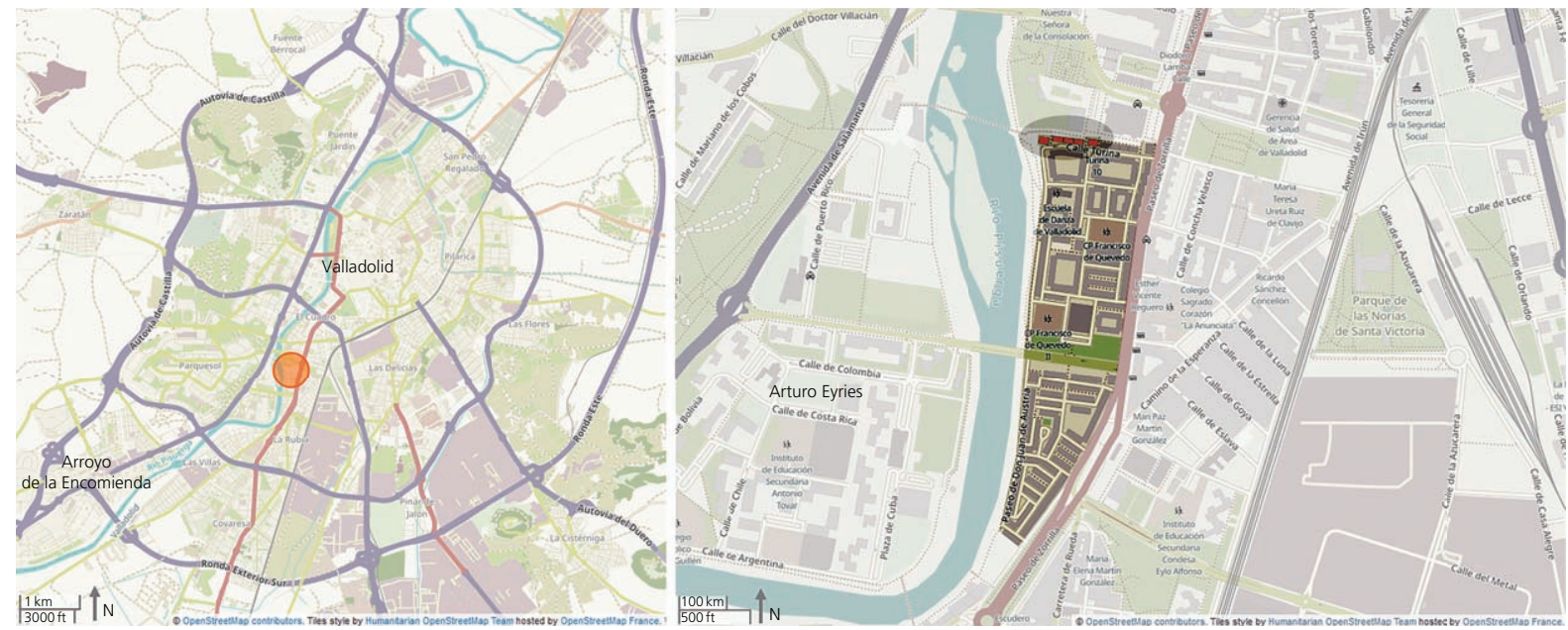

Figure 11. Location map of case study district, Cuatro de Marzo, in Valladolid (Spain) (@ OpenStreetMap contributors (OpenStreetMap, 2020))

Table 2. Detailed information of Cuatro de Marzo district

$\begin{array}{lc}\text { Altitude: } \mathrm{m} & 690 \\ \text { Number of buildings } & 183 \text { linear blocks and } 6 \text { towers } \\ \text { Number of dwellings } & 1941 \\ \text { Conditioned area: } \mathrm{m}^{2} & 166000 \\ \text { Population } & 3750 \text { inhabitants } \\ \text { Cooling degree day: }{ }^{\circ} \mathrm{C} & 394 \\ \text { Heating degree day: }{ }^{\circ} \mathrm{C} & 3121 \\ \text { Average winter temperature: }{ }^{\circ} \mathrm{C} & 5 \\ \text { Average summer temperature: }{ }^{\circ} \mathrm{C} & 20.5\end{array}$

- Prioritisation criteria. Figure 18 shows the options to choose for the prioritisation criteria. In this paper, an example of the prioritisation criteria scheme is shown, with the option selected 'to achieve a nearly zero-energy district' and prioritising economic aspects. A comparison between different prioritisation schemes can be found in the paper by García-Fuentes et al. (2019).

After the upload of all the information required to the platform, the optimisation process is launched and the Pareto front, shown in Figure 19, is obtained with the execution of ten iterations and ten scenarios per iteration. With this case study, a complete validation of the platform prototype is performed.

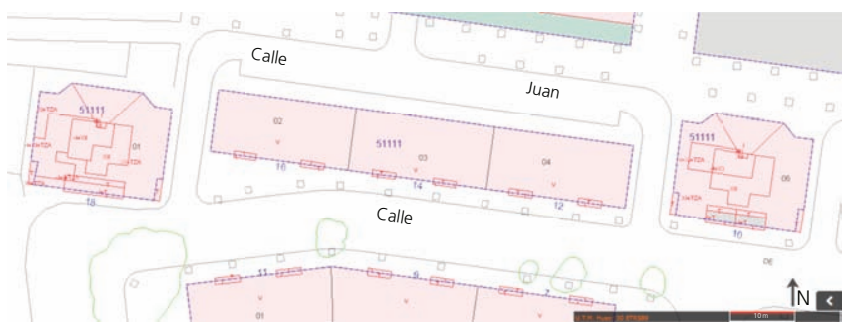

Figure 12. Floor plan layout of the five selected buildings (source: Spanish Cadastre) (DGC, 2020)

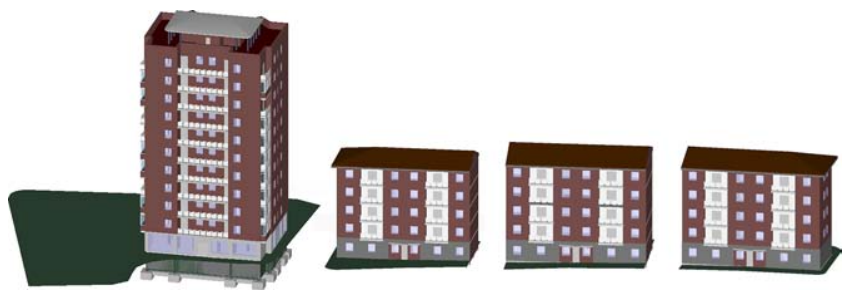

Figure 13. IFC models generated: one tower and three different blocks

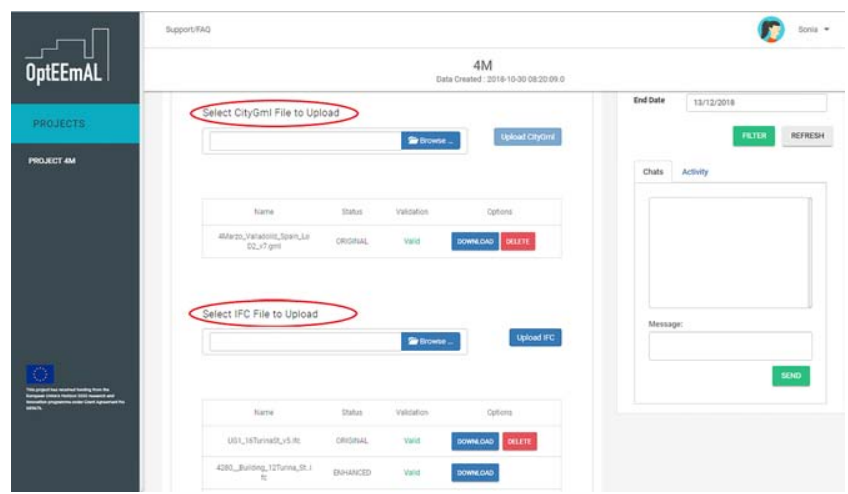

Figure 14. Insert CityGML and IFC files interface in the project Cuatro de Marzo with the user data input module

Some results related to one of the chosen optimal scenario (scenario 1) are presented in Figure 20 (energy demand and final energy consumption)in comparison with the results for the baseline condition of the district. These results have been exported through the platform in an Excel file.

A deeper analysis of the results obtained for the Cuatro de Marzo district can be done by comparing the available information of the 
Smart Infrastructure and Construction Volume 172 issue 3
Software solution to design energyefficient retrofitting projects at district scale

Martín-Toral, Serna-González, Álvarez-Díaz et al.

\section{Building Level Questions}

Please answer these questions for each building. You may select multiple buildings before answering, to apply the answers to multiple buildings.

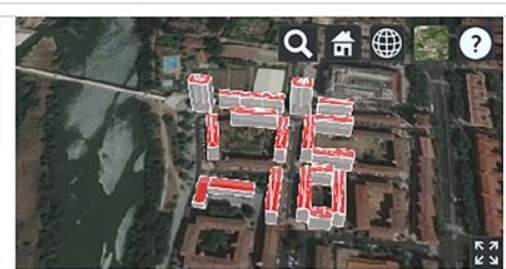

Buildings

$\square$ 4280_Building_..

$\square$ 4281_Building_...

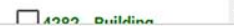

DESELECT ALL

Figure 15. Three-dimensional representation of the Cuatro de Marzo district with the 3D visualisation module. Building energy systems' data collection interface

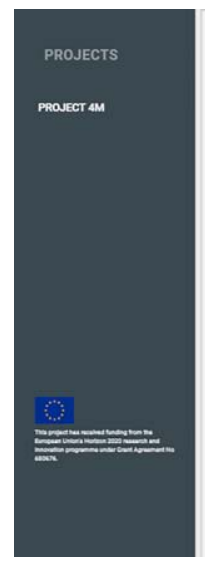

\section{Contextual Data}

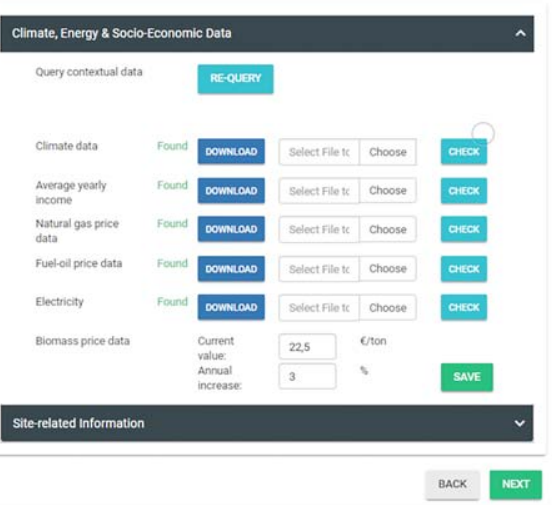

Figure 16. Contextual data interface included in the user data input module

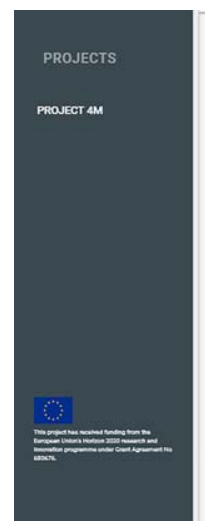

Targets and Boundaries

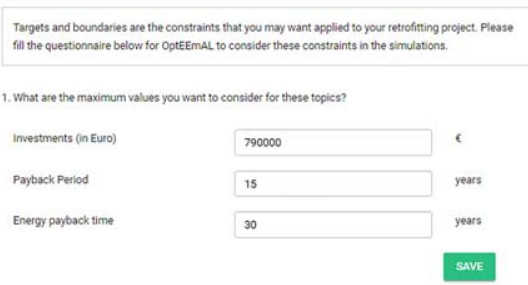

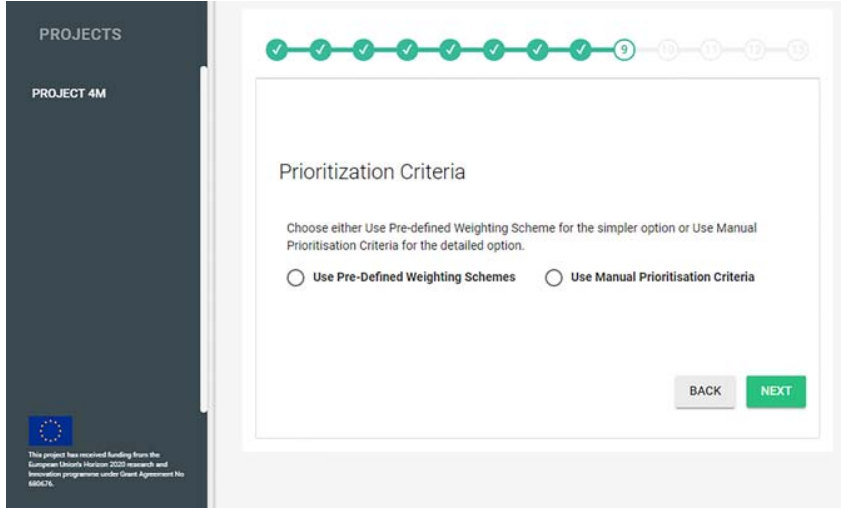

Figure 18. Prioritisation criteria interface

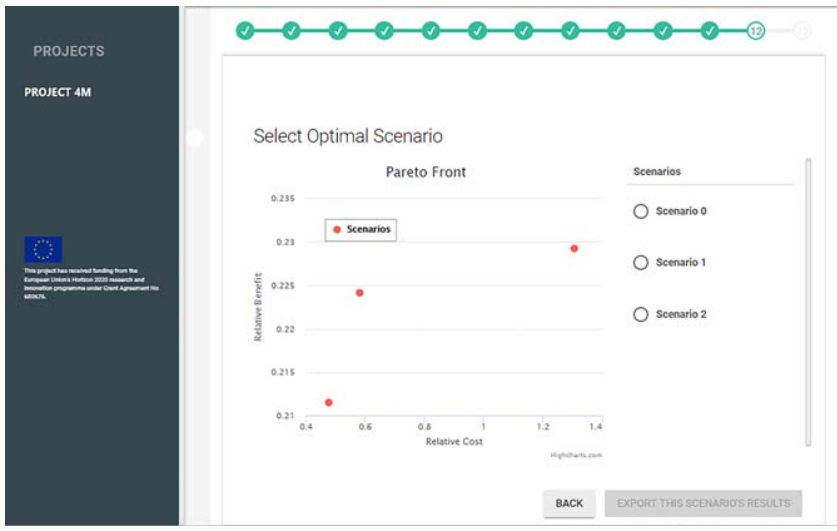

Figure 19. Select optimal scenario interface with the Pareto Front obtained in the project Cuatro de Marzo

district coming from the R2Cities project and the ECMs proposed by the OptEEmAL platform (R2Cities Consortium, 2018). This comparison is shown in Table 3.

\section{Interpretation and discussion}

This paper has presented the main objectives of the OptEEmAL platform and how the technical challenges to pursue these objectives have been tackled. Of particular relevance is the approach followed in the platform design, implementation and deployment, where a (micro)service-oriented platform, using an enterprise service bus to connect and synchronise different and asynchronous modules, has been deployed on several environments. This connection and synchronisation would not have been possible without relying on a DDM based on standards that can ensure interoperability among the modules of the platform. It enables representation of the baseline scenario and the different enriched models including a combination of ECMs. Moreover, to be able to support the design of energy retrofitting solutions, an important advancement proposed by the OptEEmAL platform is the automatic generation of scenarios based on the combination of ECMs and the optimisation based on previously 


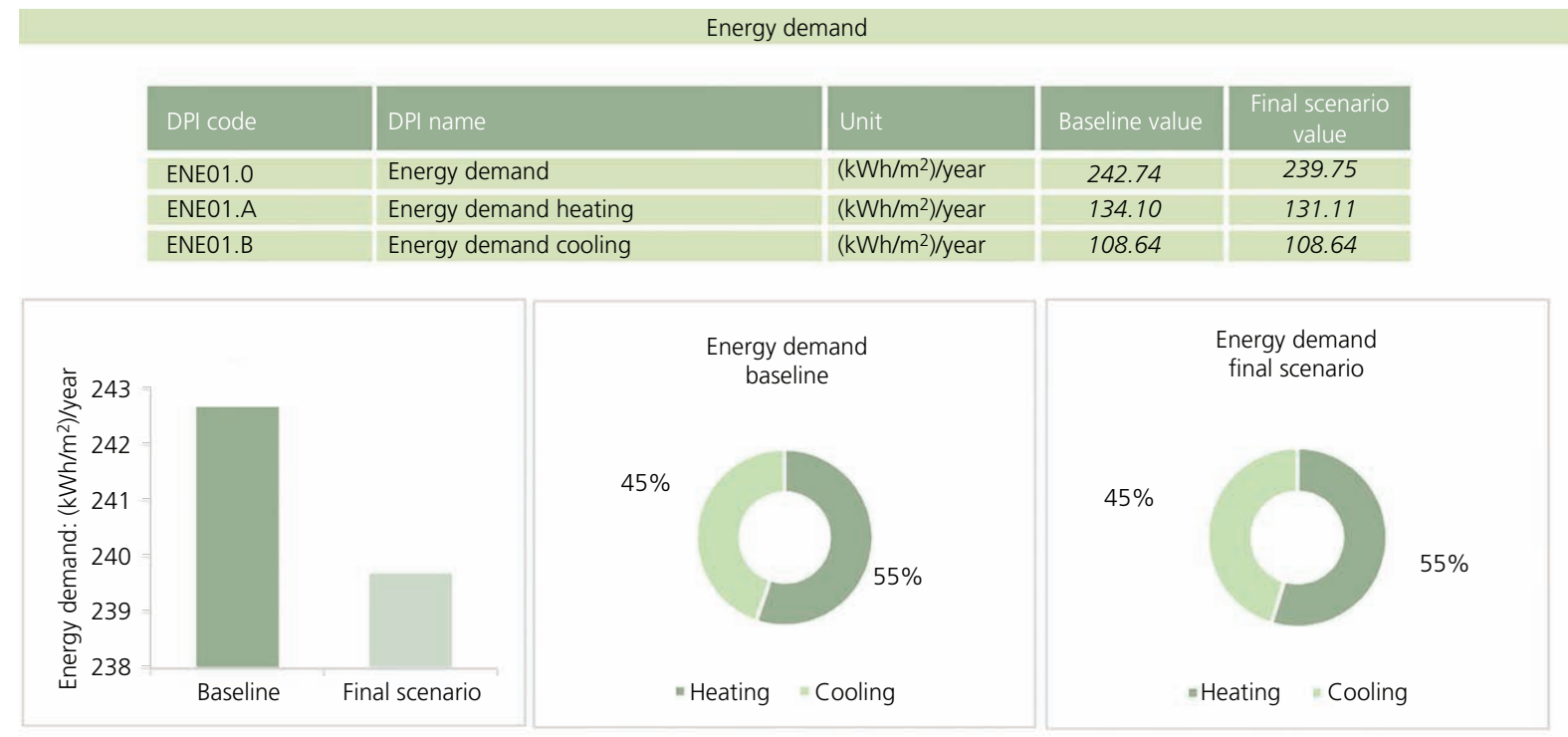

(a)

Final energy consumption

\begin{tabular}{|c|c|c|c|c|}
\hline DPI code & DPI name & Unit & Baseline value & $\begin{array}{c}\text { Final scenario } \\
\text { value }\end{array}$ \\
\hline ENE02.0 & Final energy consumption & $\left(\mathrm{kWh} / \mathrm{m}^{2}\right) /$ year & 141.81 & 78.17 \\
\hline ENE02.A & Final energy consumption (thermal) & $\left(\mathrm{kWh} / \mathrm{m}^{2}\right) /$ year & 90.50 & 51.52 \\
\hline ENE02.A.1 & Final energy consumption (thermal - gas) & $\left(\mathrm{kWh} / \mathrm{m}^{2}\right) /$ year & 90.50 & 42.48 \\
\hline ENE02.A. 2 & $\begin{array}{l}\text { Final energy consumption (thermal - } \\
\text { biomass) }\end{array}$ & $\left(\mathrm{kWh} / \mathrm{m}^{2}\right) /$ year & 0.00 & 9.04 \\
\hline ENE02.A.3 & $\begin{array}{l}\text { Final energy consumption (thermal - } \\
\text { diesel) }\end{array}$ & $\left(\mathrm{kWh} / \mathrm{m}^{2}\right) /$ year & 0.00 & 0.00 \\
\hline ENEO2.B & Final energy consumption (electricity) & $\left(\mathrm{kWh} / \mathrm{m}^{2}\right) /$ year & 51.31 & 26.65 \\
\hline
\end{tabular}

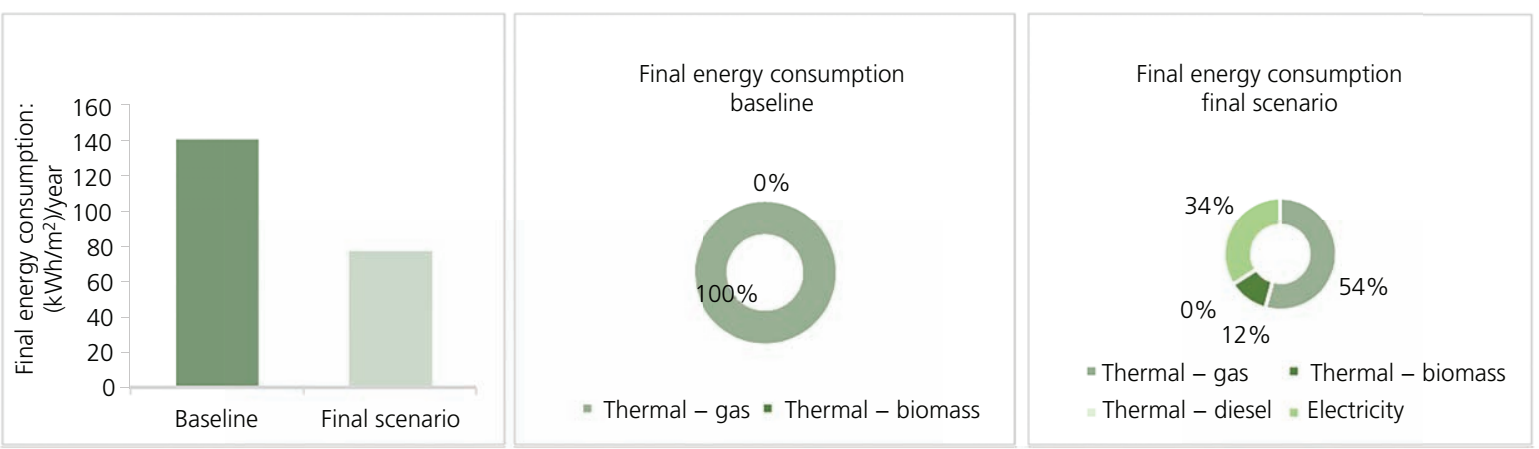

(b)

Figure 20. Energy DPIs for optimal scenario 1: (a) energy demand; (b) final energy consumption

performed simulations of the behaviour of the district, as well as the consideration of the objectives and barriers defined by the users, who interact within the platform following the IPD paradigm.

All these requirements have been reflected in this paper in the form of a high-level architecture comprising a set of modules, services, external tools and the interfaces among them. The way that these elements interact to fulfil the different OptEEmAL functionalities has been reflected in several process schemes representing the three main actions: the data insertion and diagnosis process, scenario generation and optimisation and data exportation. Finally, the GUIs for accessing these functionalities have been presented by showing real results when applying the tool in the Cuatro de Marzo district located in Valladolid (Spain). The correct operation of the OptEEmAL solution has been 
Table 3. Comparison between actually implemented and proposed ECMs by OptEEmAL in Cuatro de Marzo district

\begin{tabular}{|c|c|c|}
\hline \multirow{2}{*}{ Real ECM } & \multicolumn{2}{|c|}{ ECMs proposed by OptEEmAL } \\
\hline & Scenario 1 & Scenario 2 \\
\hline Roof insulation below top slab (rock wool $100 \mathrm{~mm}$ ) & $\begin{array}{l}\text { Passive roof pitched internal insulation } \\
\text { (mineral wool } 100 \mathrm{~mm} \text { ) }\end{array}$ & $\begin{array}{l}\text { Passive roof pitched internal insulation } \\
\text { mineral wool } 60 \mathrm{~mm} \text { ) }\end{array}$ \\
\hline Facade ETICS EPS $120 \mathrm{~mm}$ & $\begin{array}{l}\text { Passive facade external thermal } \\
\text { composite system (EPS } 150 \mathrm{~mm} \text { ) }\end{array}$ & Passive facade ETICS (EPS $250 \mathrm{~mm}$ ) \\
\hline Solar thermosiphon collectors for DHW & $\begin{array}{l}\text { Monocrystalline photovoltaic panel } \\
\text { connected to the grid, } 320 \mathrm{~W}\end{array}$ & $\begin{array}{l}\text { Monocrystalline photovoltaic panel } \\
\text { connected to the grid, } 320 \mathrm{~W}\end{array}$ \\
\hline $\begin{array}{l}\text { Efficient condensation low-temperature boiler for } \\
\text { heating and support of DHW, } 24 \mathrm{~kW}\end{array}$ & $\begin{array}{l}\text { Condensing natural gas boiler with } \\
24 \mathrm{~kW} \text { of nominal capacity }\end{array}$ & $\begin{array}{l}\text { Condensing diesel boiler with } 26 \mathrm{~kW} \text { of } \\
\text { nominal capacity }\end{array}$ \\
\hline
\end{tabular}

DHW, domestic hot water; EPS, expanded polystyrene; ETICS, external thermal insulation composite system

validated and demonstrated at technical and societal levels in three different TRLs, from TRL5 to TRL7, with Cuatro de Marzo district being one of the case studies validated for TRL6.

Based on the results obtained, it is demonstrated that the tool improves the business-as-usual processes. First of all, time is dramatically reduced, as well as the errors. By not having to model manually all the simulation models that include all the potential ECMs to be considered and instead automatically generating and simulating these scenarios, a great amount of time is saved (from several weeks to $30 \mathrm{~h}$ for the Cuatro de Marzo case (OptEEmAL Consortium, 2019a)) and more accurate results are obtained (human intervention is prone to errors). This reduction in time also fosters a reduction in costs $(50 \%$ estimated for the design phase (OptEEmAL Consortium, 2019a)), together with the optimisation of the investment driven by the optimal retrofitting solution proposed by the tool. In addition to this, a bigger amount of ECMs can be tested, leading to more informed and robust decisions. The only requirement that is needed to launch this process is input data, which should be modelled following IFC and CityGML standards and in a specific way. In order to ease this process, guidelines have been developed. However, even though this can be seen as a weakness, together with the complexity of the platform, it reflects the trends that are followed in the building sector (e.g. the increasing use of BIM), which will continue to consolidate in the following years.

The combination of all these innovations will allow the attainment of the following benefits.

- OptEEmAL will deliver a more effective refurbishment at building and district levels, achieving time reduction during design and construction phases and improving quality, comfort and maintenance activities.

- OptEEmAL will enable actors to make validated and quantified selections for the optimised design for refurbishment plans at building and district levels.

- OptEEmAL will contribute to mobilisation of public and private investments through better decision-making procedures, more effective design and operation phases, as well as contribute to economic savings.
- OptEEmAL will enhance the utilisation of innovative and existing solutions in a holistic integration, enhancing the access to applied research and technology transfer such as new technologies, materials, smart and eco-efficient solutions.

- OptEEmAL will contribute to following the contractual processes established by the IPD methodology through BIM adoption, contributing to the EU public procurement directive principles and improving the competitiveness of the European construction sector in the field of 'green' construction technologies (EC, 2014).

- OptEEmAL will overcome non-technical barriers preventing the implementation of energy-efficient retrofitting projects, such as the difficulties of persuading owners, the quantification of effective economic savings and the lack of exhaustive information.

All in all, time, errors and inconsistencies in the design and refurbishment of district retrofitting projects will be reduced, leading, thus, to increasing efficiency and to generating confidence among stakeholders. This will result, as a consequence, in a greater number of retrofits, which will contribute to the reduction in carbon dioxide emissions.

\section{Conclusions}

The work presented in this paper has resulted in the generation of a tool that enables solving the most commonly encountered problem in retrofitting projects: finding the best retrofitting solution.

The integrated functionalities of OptEEmAL have been reached by progressing in several areas of innovation.

- OptEEmAL integrates relevant issues and stakeholders so that important information for the design of district retrofitting plans are taken into account within a single framework, providing support for the implementation of a holistic and integrated approach which is not possible with currently available tools.

- OptEEmAL allows the definition and evaluation of refurbishment scenarios of districts, taking into account environmental, economic and social indicators. 
- OptEEmAL takes advantage of geo-clustering techniques, providing automatic answers to climate and energy price queries with the creation of a specific geospatial information database.

- The OptEEmAL platform integrates a multi-objective optimisation module based on evolutionary algorithms, to define and evaluate automatically retrofitting scenarios at the district level.

- OptEEmAL combines and integrates multidisciplinary and diverse data sources. The Semantic Web technology implemented enables the transformation of the captured data into meaningful information.

- The outputs of the whole OptEEmAL tool are planned to be part of the decision-making/best-alternative-selection optimisation process to identify the best retrofitting configuration while respecting stakeholder requirements.

\section{Acknowledgements}

The authors would like to acknowledge the rest of the OptEEmAL partners, for their support in this project. This research work has been partially funded by the European Commission through the EU's Horizon 2020 Research and Innovation Programme under grant agreement number 680676. All related information to the project is available at the website of the OptEEmAL Consortium (2021).

\section{REFERENCES}

AIACC (American Institute of Architects, California Council) (2014) Integrated Project Delivery: an Updated Working Definition. AIACC, Sacramento, CA, USA.

Berkeley P, Haves P and Kolderup E (2015) The effect of modeller decisions on simulation uncertainty: some implications for user interface design. Proceedings of BS2015: 14th Conference of International Building Performance Simulation Association, Hyderabad, India, pp. 2923-2930.

De Tommasi L, Ridouane H, Giannakis G et al. (2018) Model-based comparative evaluation of building and district control-oriented energy retrofit scenarios. Buildings 8(7): article 91, https://doi.org/10.3390/ buildings 8070091 .

DGC (Dirección General del Catastro) (2020) See http://www.catastro. minhap.gob.es/ (accessed 26/08/2020).

EC (European Community) (2012) Directive 2012/27/EU of the European Parliament and of the Council of 25 October 2012 on energy efficiency, amending Directives 2009/125/EC and 2010/30/EU and repealing Directives 2004/8/EC and 2006/32/EC. Official Journal of the European Union L315/1.

EC (2014) Directive 2014/24/EU of the European Parliament and of the Council of 26 February 2014 on public procurement and repealing Directive 2004/18/EC. Official Journal of the European Union L94/65.

EC (2018) Directive (EU) 2018/844 of the European Parliament and of the Council of 30 May 2018 amending Directive 2010/31/EU on the energy performance of buildings and Directive 2012/27/EU on energy efficiency. Official Journal of the European Union L156/75.

García-Fuentes MA, Hernández G, Serna V and Vicente J (2016) OptEEmAL: una herramienta de diseño para proyectos de rehabilitación de áreas urbanas hacia distritos de energía casi nula. In Proceedings of 3er Congreso de Edificios de Energía Casi Nula (Grupo Tecma Red SL (eds)). Libro de Comunicaciones, Madrid, Spain, pp. 443-448 (in Spanish).

García-Fuentes M, Serna V and Hernández G (2018) Evaluation and optimisation of energy efficient retrofitting scenarios for districts based on district performance indicators and stakeholders' priorities.
Proceedings of BSO 2018: 4th Building Simulation and Optimization Conference, Cambridge, Cambridge, UK, pp. 68-75.

García-Fuentes MÁ, Álvarez S, Serna V, Pousse M and Meiss A (2019) Integration of prioritisation criteria in the design of energy efficient retrofitting projects at district scale: a case study. Sustainability 11(14): article 3861, https://doi.org/10.3390/su11143861.

Gee L and Dijol J (2013) Financing nearly zero energy housing projects. Power House Nearly Zero Energy Challenge. NHF \& CECODHAS Housing Europe, Brussels, Belgium.

Giannakis G, Kontes G, Korolija I and Rovas D (2017) Simulation-time reduction techniques for a retrofit planning tool. Proceedings of the 17th IBPSA Conference, San Francisco, CA, USA, pp. 2014-2023.

Giannakis Gl, Katsigarakis K, Lilis GN and Álvarez-Díaz S (2019) Guidelines for OptEEmAL BIM Input Files. OptEEmAL Consortium, Valladolid, Spain. See https://www.OptEEmAL-project.eu/presscorner/publications/further-downloads.html (accessed 14/05/2019).

Gruber T (1993) A translation approach to portable ontology specifications. Knowledge Acquisition 5(2): 199-220, https://doi.org/ 10.1006/knac.1993.1008.

Hernández G, Serna V and García-Fuentes MÁ (2017) Design of energy efficiency retrofitting projects for districts based on performance optimization of District Performance Indicators calculated through simulation models. Energy Procedia 122: 721-726, https://doi.org/10. 1016/j.egypro.2017.07.386.

ISO (International Organization for Standardization) (2013) ISO 163791:2018: Industry Foundation Classes (IFC) for data sharing in the construction and facility management industries - Part 1: Data schema. ISO, Geneva, Switzerland.

Katsigarakis K, Lilis GN, Giannakis G and Rovas D (2019) An IFC data preparation workflow for building energy performance simulation. In Proceedings of the 2019 European Conference on Computing in Construction (EC3) (O'Donnell J, Chassiakos A, Rovas D and Hall D (eds)). European Council on Computing in Construction, Chania, Crete, Greece, pp. 164-171.

Lilis GN, Giannakis G, Katsigarakis K and Rovas DV (2018) A tool for IFC building energy performance simulation suitability checking. In eWork and eBusiness in Architecture, Engineering and Construction: Proceedings of the 12th European Conference on Product and Process Modelling (ECPPM 2018), September 1--14, 2018, Copenhagen, Denmark (Karlshøj J and Scherer R (eds)). CRC Press/Balkema, Leiden, the Netherlands, pp. 57-64.

Lonsdale D, Embley DW, Ding Y, Xu L and Hepp M (2010) Reusing ontologies and language components for ontology generation. Data \& Knowledge Engineering 69(4): 318-330, https://doi.org/10.1016/j. datak.2009.08.003.

Ma Z, Copper P, Daly D and Ledo L (2012) Existing building retrofits: methodology and state-of-the-art. Energy Build 55: 889-902, https:// doi.org/10.1016/j.enbuild.2012.08.018.

Madrazo L, Sicilia A and Gamboa G (2012) SEMANCO: semantic tools for carbon reduction in urban planning. In eWork and eBusiness in Architecture, Engineering and Construction: Proceedings of the European Conference on Product and Process Modelling 2012, Reykjavik, Iceland, 25-27 July 2012 (Gudnason G and Scherer R (eds)). CRC Press/Balkema, Leiden, the Netherlands, pp. 899-908.

Manjarres D, Mabe L, Oregi X, Landa-Torres I and Arrizabalaga E (2017) A multi-objective harmony search algorithm for optimal energy and environmental refurbishment at district level scale. In Harmony Search Algorithm: Proceedings of the 3rd International Conference on Harmony Search Algorithm (ICHSA 2017) (Del Ser J (ed.)). Springer, Singapore, pp. 320-332.

Martín S, Serna VI, Álvarez S et al. (2019) OptEEmAL: IT-supported design tool for the generation of optimised energy retrofitting scenarios at district level. In Proceedings of the 2019 European Conference on Computing in Construction (EC3) (O'Donnell J, 
Smart Infrastructure and Construction

Volume 172 issue 3
Software solution to design energy-

efficient retrofitting projects at district

scale

Martín-Toral, Serna-González, Álvarez-Díaz et al.
Chassiakos A, Rovas D and Hall D (eds)). European Council on Computing in Construction, Chania, Crete, Greece, pp. 246-255.

O’Donnell J, See R, Rose C et al. (2011) SimModel: a domain data model for whole building energy simulation. Proceedings of Building Simulation 2011: 12th Conference of International Building Performance Simulation Association, Sydney, Australia, pp. 382-389. OGC (Open Geospatial Consortium) (2012) OGC City Geography Markup Language (CityGML) Encoding Standard. OGC, Wayland, MA, USA. See http://www.opengis.net/spec/citygml/2.0 (accessed 20/06/2019).

OpenStreetMap (2020) See https://www.openstreetmap.org (accessed 08/12/2020).

OptEEmAL Consortium (2016a) D5.1: Platform high-level architecture. OptEEmAL Consortium, Valladolid, Spain.

OptEEmAL Consortium (2016b) D1.2: Requirements and Specification of Input Data Process to Evaluate Users Objectives and Current Conditions. OptEEmAL Consortium, Valladolid, Spain. See https:// www.OptEEmAL-project.eu/press-corner/publications/deliverables. html (accessed 26/08/2020).

OptEEmAL Consortium (2016c) D1.3: Requirements and Specification of Geoclustering Data Sets Access Module. OptEEmAL Consortium, Valladolid, Spain. See https://www.OptEEmAL-project.eu/presscorner/publications/deliverables.html (accessed 26/08/2020).

OptEEmAL Consortium (2016d) D2.1: Requirements and Specification for the District Data Model. OptEEmAL Consortium, Valladolid, Spain. See https://www.OptEEmAL-project.eu/press-corner/publications/ deliverables.html (accessed 26/08/2020).

OptEEmAL Consortium (2016e) D3.1: Requirements and Specification of the ECMs Catalogue. OptEEmAL Consortium, Valladolid, Spain. See https://www.OptEEmAL-project.eu/press-corner/publications/ deliverables.html (accessed 26/08/2020).

OptEEmAL Consortium (2016f) D4.4: Requirements and Design of Simulation Model Input Generator Module. OptEEmAL Consortium, Valladolid, Spain. See https://www.OptEEmAL-project.eu/presscorner/publications/deliverables.html (accessed 26/08/2020).

OptEEmAL Consortium (2016g) D4.1: Requirements and Design of the Optimisation Module. OptEEmAL Consortium, Valladolid, Spain. See https://www.OptEEmAL-project.eu/press-corner/publications/ deliverables.html (accessed 26/08/2020).

OptEEmAL Consortium (2016h) D5.2: Functional architecture specification, interfaces definition and overall platform design. OptEEmAL Consortium, Valladolid, Spain.
OptEEmAL Consortium (2018a) D4.2: Optimisation Module Prototype. Valladolid. OptEEmAL Consortium, Valladolid, Spain.

OptEEmAL Consortium (2018b) D5.3: Functional modules and interfaces development and testing. OptEEmAL Consortium, Valladolid, Spain.

OptEEmAL Consortium (2019a) D6.2: Report on Platform Prototype Demonstration in Relevant Environment. OptEEmAL Consortium. See https://www.OptEEmAL-project.eu/press-corner/publications/ deliverables.html (accessed 26/08/2020).

OptEEmAL Consortium (2019b) D6.4: Report on Platform Demonstration in the Demo Cases. OptEEmAL Consortium. See https://www. OptEEmAL-project.eu/press-corner/publications/deliverables.html (accessed 26/08/2020).

OptEEmAL Consortium (2021) See https://www.OptEEmAL-project.eu (accessed 14/01/2021)

Ozarisoy B and Altan H (2019) Low-energy design strategies for retrofitting existing residential buildings in Cyprus. Proceedings of the Institution of Civil Engineers - Engineering Sustainability 172(5): 241-255, https://doi.org/10.1680/jensu.17.00061.

Ozarisoy B and Elsharkawy H (2019) Assessing overheating risk and thermal comfort in state-of-the-art prototype houses that combat exacerbated climate change in UK. Energy and Buildings 187: 201-217, https://doi.org/10.1016/j.enbuild.2019.01.030.

Pauwels P, Corry E and O'Donnell J (2014) Representing SimModel in the web ontology language. In Computing in Civil and Building Engineering: Proceedings of the 2014 International Conference on Computing in Civil and Building Engineering (Issa R and Flood I (eds)). American Society of Civil Engineers, Reston, VA, USA, pp. 2271-2278.

R2Cities Consortium (2018) D5.2: Report of the energy performance analysis. R2Cities Consortium, Valladolid, Spain.

R2Cities Consortium (2019) See http://r2cities.eu/ (accessed 27/06/2019).

Sauer B and Pedrola B (2014) First Survey of Existing Tools and Methods Supporting Evaluation Indicators for Urban District Retrofitting and Renewal. s.1.: ECODISTR-ICT project. See https://cordis.europa.eu/ project/id/608913/reporting.

Sicilia Á and Costa G (2017) Energy-related data integration using semantic data models for energy efficient retrofitting projects. Proceedings 1(7): article 1099, https://doi.org/10.3390/ proceedings 1071099 .

Simperl E (2009) Reusing ontologies on the Semantic Web: a feasibility study. Data \& Knowledge Engineering 68(10): 905-925.

\section{How can you contribute?}

To discuss this paper, please email up to 500 words to the editor at journals@ice.org.uk. Your contribution will be forwarded to the author(s) for a reply and, if considered appropriate by the editorial board, it will be published as discussion in a future issue of the journal.

Proceedings journals rely entirely on contributions from the civil engineering profession (and allied disciplines). Information about how to submit your paper online is available at www.icevirtuallibrary.com/page/authors, where you will also find detailed author guidelines. 